\title{
Evolution and modulation of tropical heating from the last glacial maximum through the twenty-first century
}

\author{
Carlos D. Hoyos • Peter J. Webster
}

Received: 8 November 2010/Accepted: 28 August 2011/Published online: 6 November 2011

(c) The Author(s) 2011. This article is published with open access at Springerlink.com

\begin{abstract}
Twentieth century observations show that during the last 50 years the sea-surface temperature (SST) of the tropical oceans has increased by $\sim 0.5^{\circ} \mathrm{C}$ and the area of SST $>26.5$ and $28^{\circ} \mathrm{C}$ (arbitrarily referred to as the oceanic warm pool: OWP) by 15 and $50 \%$ respectively in association with an increase in green house gas concentrations, with non-understood natural variability or a combination of both. Based on CMIP3 projections the OWP is projected to double during twenty-first century in a moderate $\mathrm{CO}_{2}$ forcing scenario (IPCC A1B scenario). However, during the observational period the area of positive atmospheric heating (referred to as the dynamic warm pool, DWP), has remained constant. The threshold SST $\left(T_{H}\right)$, which demarks the region of net heating and cooling, has increased from $26.6^{\circ} \mathrm{C}$ in the 1950 s to $27.1^{\circ} \mathrm{C}$ in the last decade and it is projected to increase to $\sim 28.5^{\circ} \mathrm{C}$ by 2100 . Based on climate model simulations, the area of the DWP is projected to remain constant during the twenty-first century. Analysis of the paleoclimate model intercomparison project (PMIP I and II) simulations for the Last Glacial maximum and the Mid-Holocene periods show a very similar behaviour, with a larger OWP in periods of elevated tropical SST, and an almost constant DWP associated with a varying $T_{H}$. The constancy of the DWP area, despite shifts in the background SST, is shown to be the result of a near exact matching between increases in the integrated convective heating within the DWP and the integrated radiative cooling outside the DWP as SST changes. Although the area of the DWP remains constant, the total tropical atmospheric heating is a strong function of the SST. For example the net heating has
\end{abstract}

C. D. Hoyos $(\bowtie) \cdot$ P. J. Webster

School of Earth and Atmospheric Sciences, Georgia Institute of Technology, 311 Ferst Drive, Atlanta, GA 30332-0340, USA

e-mail: choyos@eas.gatech.edu increased by about $10 \%$ from 1950 to 2000 and it is projected to increase by a further $20 \%$ by 2100 . Such changes must be compensated by a more vigorous atmospheric circulation, with growth in convective heating within the warm pool, and an increase of subsiding air and stability outside the convective warm pool and an increase of vertical shear at the DWP boundaries. This finding is contrary to some conclusions from other studies but in accord with others. We discuss the similarities and differences at length.

Keywords Tropical warm pool - Tropical convective heating - Tropical climate, areas of convection in last glacial maximum, Mid-Holocene and present - Projections of the warm pool for the twenty-first century

\section{Introduction}

A key to understanding the evolution of Earth's climate is deciphering the relationship between tropical convection and the magnitude and gradients of the local sea-surface temperature (SST). Although the variation of SST may not necessarily mirror changes in convection, it provides a vivid example of climate change. During the twentieth century tropical SST has increased by about $0.8^{\circ} \mathrm{C}$ in all tropical oceanic basins (Fig. 1a) in two major steps. Warming occurred through the 1930s before reaching a peak in the 1940-1945 period followed by an SST plateau of cooler temperatures for the next 20 years before warming rapidly into the present era. Whereas data was scarce early in the last century, the trend in global SST has been unambiguously positive across the century (e.g., Deser et al. 2010) whether the trend is caused by increased greenhouse gas concentrations, internal climate variability or a combination of both. 
Fig. 1 a Evolution of SST for the tropical, Pacific, Indian, and Atlantic basins in 5-year (pentad) bins from 1910 to 2004. b Same as a but for area $\left(10^{12} \mathrm{~m}^{2}\right)$ of SST $>28^{\circ} \mathrm{C}(\mathrm{OWP}$ area). c Evolution of SST $>28^{\circ} \mathrm{C}\left(10^{12} \mathrm{~m}^{2}\right)$ with the percent deviation relative to the mean annual cycle of area of SST $>28^{\circ} \mathrm{C}$. d Long-term mean annual cycle. NOAA Extended Reconstructed SST v2 data was used in this diagram (a) Observed SST

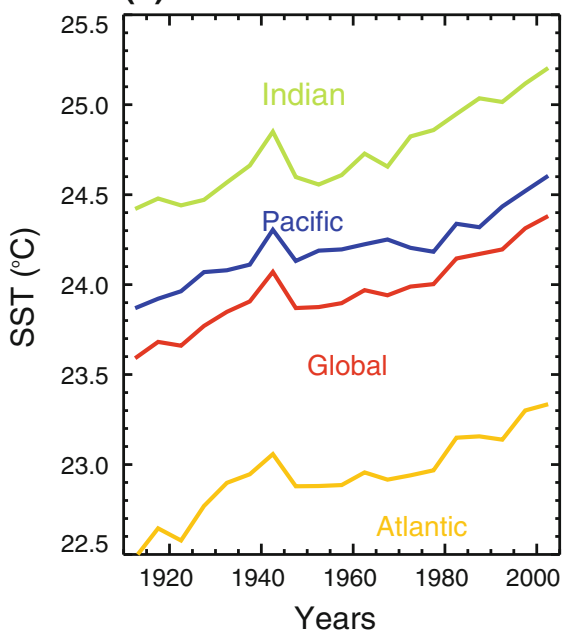

(b) Observed Area $>28^{\circ} \mathrm{C}$

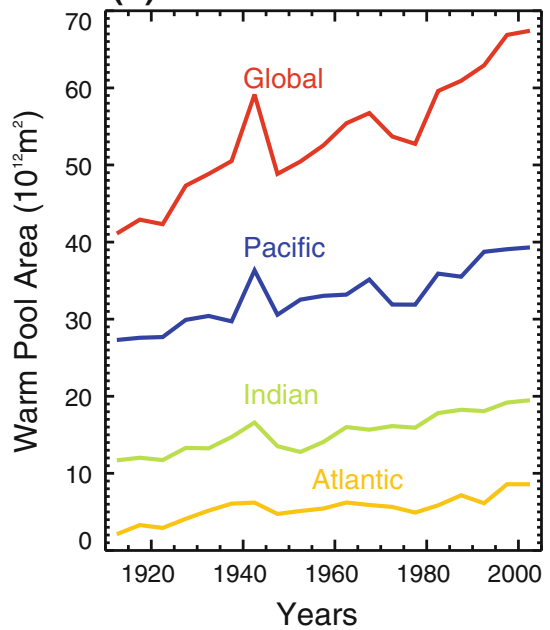

(c) Area SST $>28.0^{\circ} \mathrm{C}$

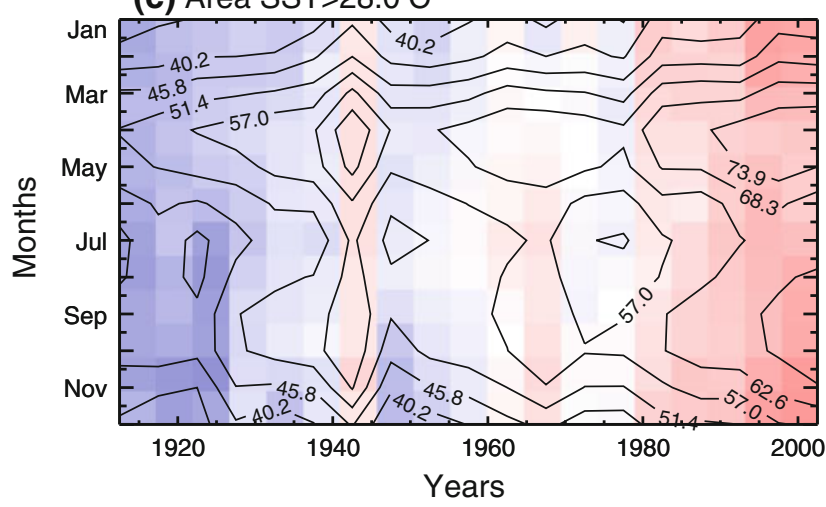

$\%$ Area Relative to Annual Cycle (d) Annual Cycle

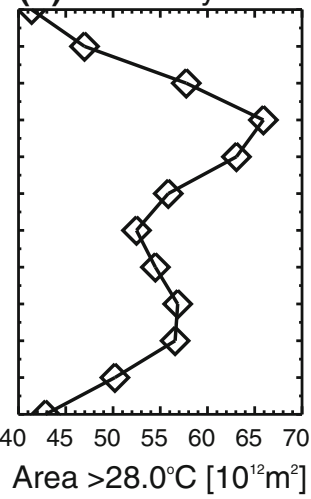

Area $>28.0^{\circ} \mathrm{C}\left[10^{12} \mathrm{~m}^{2}\right]$

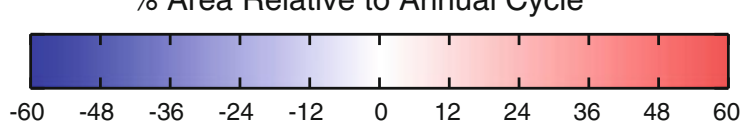

Figure $1 \mathrm{~b}$ shows the change in area of the ocean warm pool (OWP), defined arbitrarily by the $28^{\circ} \mathrm{C}$ sea-surface temperature (SST) isotherm. We will later abandon this arbitrary limit. However, the $0.8^{\circ} \mathrm{C}$ increase of tropical SST since 1910 has been accompanied by a 70\% expansion of the area of the OWP (so defined). The behaviour of each ocean basin is similar to the overall variation in the global tropics (Fig. 1b). The area of the Indian and Pacific OWPs have increased by about 80 and $50 \%$, respectively, whereas the Atlantic OWP, the smallest and coolest of the tropical ocean basins, has increased by $350 \%$. To provide a perspective, during an El Niño event the area of the Pacific OWP (i.e., the area with SST $>28^{\circ} \mathrm{C}$ ) increases by about $15 \%$. Figure $1 \mathrm{c}$ shows a time section of the annual cycle of the OWP. The increase in area is spread rather uniformly across the annual cycle. The OWP area in the 2000-2004 pentad is $\sim 40 \%$ larger than in 1980 compared to the century long climatological value. The climatological annual cycle of the OWP area (Fig. 1d) shows two peaks following the equinoxes with a maximum in April $\left(65 \times 10^{12} \mathrm{~m}^{2}\right)$ and a secondary peak in October $\left(58 \times 10^{12} \mathrm{~m}^{2}\right)$. Based on simulations using climate models forced by a number of emission scenarios (described in Special Report on Emission Scenarios: SRES, IPCC 2000) the increase of the area encompassing $28^{\circ} \mathrm{C}$ is projected to continue throughout the twenty-first century (IPCC 2007, e.g., Knutti et al. 2008).

The general increasing trend in global SSTs during the twentieth century is non-uniform with a peak occurring in the 1930-1940s period and a deep valley between 1950 and 1970. There are differing explanations for the very obvious 1930-1945 "bump" in SST and OWP area easily identifiable in Fig. 1a, and b. Thompson et al. (2008) argue that the bump is the result of an uncorrected instrumental biases in the SST record reflecting a general change from the use of bucket temperature measurements to determine SSTs 
prior to engine intake measurements generally after 1945 . However, the land temperature record in the tropics and extratropics of both hemispheres and in the Arctic (Polyakov et al. 2003) shows a general warming starting in the early 1930s up to 1945 and a fall after 1945 through 1970 with a peak to valley amplitude of about $1^{\circ} \mathrm{C}$. The dip in surface temperatures is usually attributed to an increase in aerosols (IPCC 2007). Irrespective of the cause of the mid-century climate event, it does not alter the long-term tendencies in SST and OWP area although it may raise some questions related to attribution of temperature change.

Tropical SSTs have also changed on century and millennial time scales as suggested by proxy paleoclimate data records (e.g., Gagan et al. 2004; Mayewski et al. 2004; Furtado et al. 2009). The last glacial maximum (LGM), occurring 25-16 ky BP (before present) with the coldest period near $21 \mathrm{ky} \mathrm{BP}$, is a key epoch where climate remained relatively stationary and considerably cooler than present for a prolonged period of time. After $18 \mathrm{ky} \mathrm{BP}$ the planet started to emerge from a glacial climate of low $\mathrm{CO}_{2}$ concentrations ( $\sim 200 \mathrm{ppm}$, Sigman and Boyle 2001) and large northern hemisphere ice sheets into the current warm Holocene epoch. By the Mid-Holocene period (M-HP, 6 ky BP: Mayewski et al. 2004) the continental ice sheets had disappeared and $\mathrm{CO}_{2}$ levels reached pre-industrial period (P-IP) levels ( 280 ppm, Sigman and Boyle 2001). The predominant difference in climate forcing at the time of the LGM compared to the present was due to precessional changes in Earth's orbit, producing localized changes in the distribution of incoming solar radiation (Gagan et al. 2004). Both the LGM and the M-HP are recognized as benchmark periods for climate reconstructions given the considerable amount of proxy observations available for this period.

CLIMAP (Climate Long-Range Investigation, Mapping, and Prediction; CLIMAP 1976, CLIMAP 1981) was the first international effort focused on the reconstruction of the climate state of the surface of the Earth during the LGM. According to the CLIMAP reconstructions, tropical SSTs were, on average, $\sim 2 \mathrm{~K}$ below current values, while the extratropics were significantly colder, more so in the northern hemisphere than the southern. However, changes in tropical warm pool may have been underestimated by CLIMAP. Reconciliation of LGM terrestrial data over Indonesia with ocean data suggests that the tropical Pacific may have been cooler by $2-4^{\circ} \mathrm{C}$ (Webster and Streten 1978; Lea et al. 2000; Rind 2000; Rosenthal et al. 2003; Visser et al. 2003; Gagan et al. 2004). In addition, many coupled climate models cannot reconcile CLIMAP's relatively small changes in tropical sea-surface temperature and have simulated larger changes than the CLIMAP reconstructions suggest (e.g., Pinot et al. 1999; Otto-Bliesner et al. 2009).
Also, the CLIMAP tropical ocean temperatures do not seem consistent with the much drier tropical climate suggested by New Guinea and North Australian terrestrial data (e.g., Webster and Streten 1978) or tropics-wide aridity (Pinot et al. 1999). Furthermore, some studies suggest that during the M-HP, SSTs were very similar to present day values, except at high northern latitudes and a few coastal regions, with differences within the errors associated with reconstruction methods (Rahmstorf 2002; Mayewski et al. 2004). Other studies suggest that SSTs in the Indo-Pacific oceanic warm pool may have been even $1 \mathrm{~K}$ higher than present values (Gagan et al. 2004). At more distant times in the past, Cretaceous tropical SSTs were probably warmer by 4-7 K than the present (Norris et al. 2002) but were likely to have had the same SST probability density function distribution as the current climate albeit shifted to higher temperatures (Williams et al. 2009).

During the last three decades there has been a continuing discussion of whether there is a natural limit to tropical SST. Most notable are the thermostat hypotheses first promulgated by Newell (1979) and later by Ramanathan and Collins (1991). The essence of these theories was the existence of negative feedbacks associated with cloud growth and increases in evaporation as a result of warmer SSTs. It was proposed that these processes kept the warm pool temperature within rather narrow bounds. A number of studies argued against the existence of such a thermodynamic limit (e.g., Wallace 1992; Hartmann and Michelsen 1993; Pierrehumbert 1995; Sud et al. 2008; Williams et al. 2009). In fact, in the 20 years since the publication of the Newell and Ramanathan and Collins papers the temperature of the tropical oceans has risen by about $0.3-0.35^{\circ} \mathrm{C}$ and the area of the arbitrary OWP has expanded considerably as can be seen clearly in Fig. 1a and b.

If organized convection is not bounded by some "trigger SST", so called by Williams et al. (2009), as suggested by a number of studies (e.g., Dutton et al. 2000; Sud et al. 2008) an immediate question arises. What has happened to the magnitude and location of convective activity during the twentieth century while SST has changed or what was its state during previous epochs such as the LGM and the M-HP? Furthermore, what may happen to the location and intensity of convective activity if the SST were to rise throughout the next century?

The distribution of tropical convection is probably more important from a climate perspective than the absolute value of SST itself except perhaps for its influence on marine ecosystems systems such as coral reefs and fish habitats. The distribution of tropical heating and cooling plays a crucial role in global weather and climate variability, modulating the spatial distribution of available potential energy and providing sources and sinks of internal energy. In the tropics, the column integrated heating 
(CIH) of an atmospheric column is dominated by latent heat release (e.g., Palmer and Mansfield 1984) while at higher latitudes radiative cooling to space is the dominant factor. In particular, the region of net atmospheric tropical heating, basically the area of organized tropical convection, acts as the "boiler box" of the planetary heat engine (e.g. Palmer and Mansfield 1984; Webster and Lukas 1992; Pierrehumbert 1995). The ascending branches of the Walker and Hadley circulations reside within areas of positive net heating, where precipitation exceeds evaporation and where tropical cyclones form and intensify. The subtropical anticylonic regions and the descending parts of the Walker and Hadley cells reside within this negative heating region.

The net heat input into the tropical atmosphere, or more specifically, the differential heating between the low and high latitudes, drives the atmospheric circulation that, in turn, promotes wind driven ocean circulations across all spatial and temporal scales advecting net heat poleward and maintaining the global heat balance. The energy transport driven by the dynamical response to global scale differential heating renders the climate at any location to be locally unbalanced. For example, tropical diabatic heating generates large-scale stationary waves and teleconnection patterns (e.g., Bjerknes 1969; Webster 1972; Trenberth et al. 1998) that modulate the meridional heat and momentum transports affecting extratropical weather and climate. This modulation also has consequences for numerical simulations. Erroneous representations of heating in tropical regions force systematic errors in extratropical weather (e.g. Hollingsworth et al. 1980; Simmons 1982).

A number of studies (e.g., Sun and Liu 1996; Seager and Murtugudde 1997; Loschnigg and Webster 2000; Stephens et al. 2004) have argued that the coupled dynamics of the ocean and atmosphere are necessary to determine the location and magnitude of tropical convection. It has also been argued that the SST-rainfall relationship is mostly modulated by large-scale moisture convergence arising from differential heating of the atmosphere between the warm pool and adjacent regions, large-scale subsidence induced by remote convection and the magnitude of the local surface latent heat flux (e.g. Fu et al. 1992; Webster 1994; Emanuel et al. 1994; Pierrehumbert 1995; Lau et al. 1997; Li et al. 2000). This reasoning implies that both the transition between different convective regimes, the onset of deep convection and total tropical CIH are functions not only of the local SST, but also of the three-dimensional large-scale atmospheric circulation.

During the last decade there has been a debate on whether the Hadley and Walker Circulation has decreased in intensity in the present era and will continue the same trend with further global warming (e.g., Vecchi et al. 2006;
Held and Soden 2006; Vecchi and Soden 2007) or has increased and perhaps will continue to increase in intensity in the future (e.g., Mitas and Clement 2005, 2006; Meng et al. 2011; Zhou et al. 2011). These are fundamental questions that are addressed in this paper.

In summary, the SST distribution has varied in the past as well as during the present era, and there is a high probability of changes occurring during the next century. However, a number of fundamental questions still remain unanswered. How has large-scale convection, paramount in the heating of the tropical atmosphere varied in the past and how it will vary in the future? Did the intensity of convection increase, decrease or remain the same as the magnitude of the SST waxed and waned? Did the area of heating expand or contract as the SST patterns changed? Clearly, the location, size and magnitude of the area of positive heating are critical pieces of information that determine the character of the Hadley, Walker and monsoon circulations and teleconnections to higher latitudes. A major thrust of this paper is to sort out the relationships between the SST and regions of positive and negative net heating in order to see if the characteristics of the tropical atmosphere in the past and present can be explained consistently and the future changes anticipated from a physical a priori basis.

In the next section we outline our methodology and describe the data and models used in the study. Results of the study of reanalysis data sets and the output from coupled climate models are presented in Sect. 3. In Sect. 4, simple theoretical and intermediate numerical models are developed to aid in deciphering the results from data analysis and from complex coupled models. A summary of the results is given in Sect. 5 .

\section{Data and methodology}

The NOAA extended reconstructed SST data set (Smith and Reynolds 2004) is used to examine twentieth century variations of SST and the OWP in the 1910-2004 period. Although the data set is available from 1854 to the present, tropical SST measurements before 1910, especially over the Pacific Ocean, are scarce (e.g., Deser et al. 2010). The reconstructed SST, initially constructed by Oberhuber (1988), is available globally on a $2^{\circ}$ grid and is constructed using the available International Comprehensive OceanAtmosphere Data Set SST data at http://www.ncdc.noaa. gov/oa/climate/coads/.NCEP-NCAR (Kalnay et al. 1996) and ECMWF ERA-40 (Uppala et al. 2005) reanalysis data sets, both available on a global $2.5^{\circ}$ grid and extending from 1948 to present and 1957-2002, respectively, are used to derive fields of CIH. Following Nigam (1994), the threedimensional heating rate, $\dot{Q}$, is calculated as a residual in 
the thermodynamic equation using the monthly fields of both reanalyses, i.e.

$$
\begin{aligned}
\dot{Q}= & \frac{\Delta T}{\Delta t}+\overline{\mathbf{v}} \cdot \nabla \bar{T}+\left(\frac{p}{p_{0}}\right)^{R / C_{p}} \overline{\bar{\omega}} \frac{\partial \bar{\Theta}}{\partial p} \\
& +\left(\frac{p}{p_{0}}\right)^{R / C_{p}}\left(\nabla \cdot \overline{\mathbf{v}^{\prime} \Theta^{\prime}}+\frac{\partial\left(\overline{\omega^{\prime} \Theta^{\prime}}\right)}{\partial p}\right)
\end{aligned}
$$

where, $\omega$ is the vertical velocity, $T$ temperature, $t$ time, $p$ pressure, $R$ the gas constant of air, $C_{p}$ the specific heat at constant pressure and $\Theta$ the potential temperature. The overbar denotes a monthly average and prime represents the departure of the 6-h analysis from the monthly average. Given the approximate thermodynamic balance in the tropics between convective heating rate $\dot{Q}$ and $\bar{\omega} \partial \bar{\Theta} / \partial p$ (Charney 1969), the heating directly associated with convection $\dot{Q}_{c}$ is given by: $\overline{\dot{Q}}=\left(p / p_{0}\right)^{R / c_{p}} \bar{\omega} \partial \bar{\Theta} / \partial p$. Subsequently, derivations of the three-dimensional heating structure will be restricted to the third term in Eq. 1. It is very difficult to obtain 6-hourly data from the different model paleoclimate and twentieth and twenty-first century model simulations whereas calculations of convective heating are quite straightforward. This simplification will facilitate intercomparison of reanalysis products and the output form different models.

Three different sets of numerical simulations are also used to assess changes of the tropical OWP and tropical heating. These are (1) the NCAR Parallel Climate Model (PCM) twentieth century simulations, (2) the World Climate Research Programme's (WCRP) Coupled Model Intercomparison Project phase 3 (CMIP3) twentieth and twenty-first century runs and (3) the Paleoclimate Modeling Intercomparison Project (PMIP) LGM and M-HP (M-HP) simulations.

Simulations from the World Climate Research Programme's (WCRP) Coupled Model Intercomparison Project Phase 3 (CMIP3, Meehl et al. 2007) are used to investigate the variability of twentieth century OWP, the magnitude and location of the convective threshold temperature $T_{H}$, separating convective from non-convective regions, and $\mathrm{CIH}$, as well as their potential changes during the twenty-first century. The analysis include CMIP3 simulations under four different IPCC emissions scenarios (IPCC 2007): (1) twentieth century simulations with corresponding anthropogenic and natural forcing, (2) twentyfirst century simulation with $\mathrm{CO}_{2}$ concentrations fixed at year $2000\left(\mathrm{CO}_{2} \sim 360 \mathrm{ppm}\right.$, COMMIT scenario), (3) twenty-first century simulation with $\mathrm{CO}_{2}$ concentrations $\sim 700 \mathrm{ppm}$ by 2100 (A1B scenario), and (4) twenty-first century simulation with $\mathrm{CO}_{2}$ concentrations $\sim 820 \mathrm{ppm}$ by 2100 (A2 scenario). The CMIP3 dataset was obtained from the Program for Climate Model Diagnosis and
Intercomparison (PCMDI; http://www-pcmdi.llnl.gov/) through the WCRP CMIP3 site (https://esg.llnl.gov:8443/).

The coupled simulations of PMIP I and II (Jousauume et al. 1999; Pinot et al. 1999; Pausata et al. 2009) are used to explore the state of the OWP and tropical heating during the LGM and M-HP. Although the solar forcing is not at a maximum during the M-HP (Mayewski et al. 2004), this period is preferred in PMIP simulations over the earlier Holocene since it is not influenced by remnant continental ice sheets from the previous glaciation. PMIP simulations consist of atmospheric-only and coupled simulations using a set of boundary conditions prepared to represent LGM and M-HP climates. In particular, external forcing includes the corresponding $\mathrm{CO}_{2}$ concentrations for each period, orbital parameters resulting in insolation changes and ice sheet extension. For the LGM experiment, ice sheet extent and height is provided by Peltier (1994) and the atmospheric $\mathrm{CO}_{2}$ concentration is prescribed to be $200 \mathrm{ppm}$ as inferred from Antarctic ice cores (Raynaud et al. 1993; Sigman and Boyle 2001). Earth's orbital parameters were changed according to their values at $21 \mathrm{ky} \mathrm{BP}$, but the insolation changes were small for this time period. For the M-HP the $\mathrm{CO}_{2}$ concentration was prescribed at the P-IP value of 280 ppm (Raynaud et al. 1993; Sigman and Boyle 2001). The main change in the incoming solar radiation in this period is due to the displacement of the longitude of the perihelion (Berger 1978), which intensifies the seasonal north-south gradient of incoming solar radiation. SSTs are either prescribed using CLIMAP for LGM and present day SST for the M-HP, or computed by coupling the atmospheric model to a slab mixed-layer ocean.

\section{Results}

The distribution and magnitude of tropical latent heat release in deep convection is, in any given period, strongly associated with the distribution of SST. Figure 2a shows the long-term average (1979-2001) SST distribution with contours of column-integrated atmospheric heating $(\mathrm{CIH})$ for the same period superimposed. Warm waters straddle the equator, extending from the Indian Ocean, across the Indonesian Archipelago into the western Pacific with a secondary area in the eastern Pacific crossing Central America into the Caribbean and the central Atlantic Ocean. The CIH patterns have a distinct SST signature: contours of CIH closely follow those of SST with regions of net positive CIH confined to areas of warmest ocean water. Figure $2 \mathrm{~b}$ shows the total tropical $\mathrm{CIH}\left(\mathrm{PW}\right.$ : $10^{15} \mathrm{~W}$ ) between $30^{\circ} \mathrm{S}$ and $30^{\circ} \mathrm{N}$. Spatially averaged $\mathrm{CIH}\left(\mathrm{Wm}^{-2}\right)$, plotted in $1^{\circ} \mathrm{C}$ SST bins for the period 1979-2001. For this period, heating of the atmospheric column occurs within the $27^{\circ} \mathrm{C}$ SST isotherm, which is the threshold SST 
(a) Mean SST ( $\left.{ }^{\circ} \mathrm{C}\right)$ and Column Integrated Heating (1979-2001)

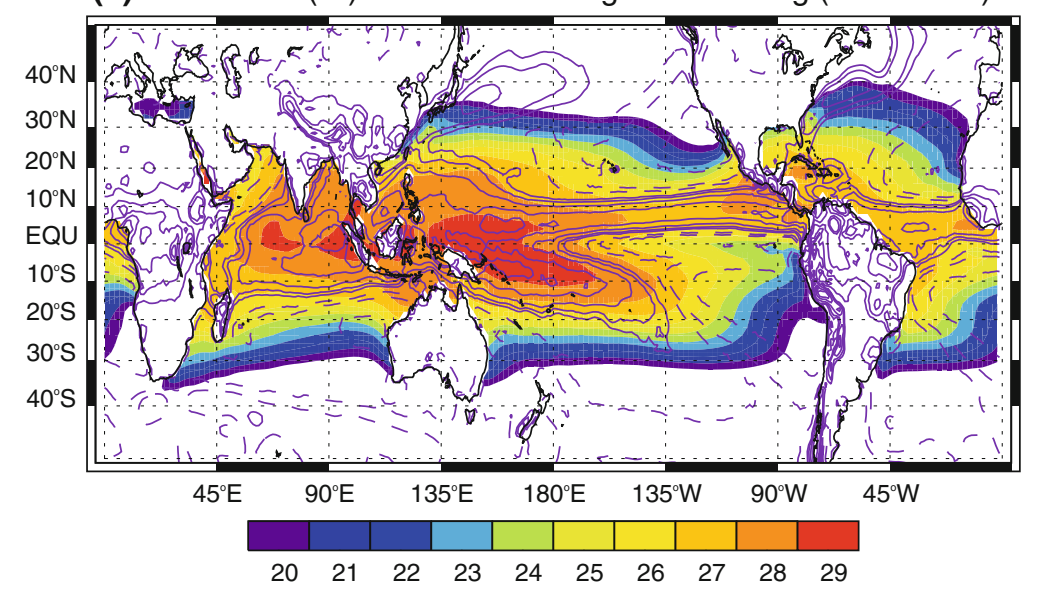

(b) $\mathrm{CIH} \&$ Average heating

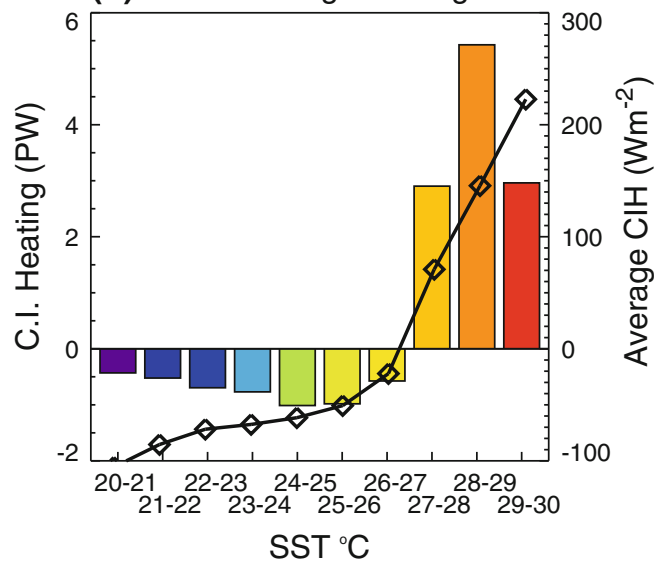

Fig. 2 a Long-term annual mean SST distribution (1979-2001) using NOAA Extended Reconstructed SST v2 data. The continuous black contours represent positive column integrated heating $(\mathrm{CIH})$, the dashed contours negative $\mathrm{CIH}$ Contours are plotted for $\pm 20,50,100$, 200 , and $300 \mathrm{Wm}^{-2}$. The column integrated heating is from the ERA40 Atlas computed using the modelled net temperature tendencies.

bounding the area of large-scale organized tropical convection from adjacent regions of cooling. More intense heating, represented by values of spatially averaged $\mathrm{CIH}$ greater than $150 \mathrm{Wm}^{-2}$, occurs in regions, where SST $>28^{\circ} \mathrm{C}$ (Fig. 2b). Traditionally, the $28^{\circ} \mathrm{C}$ temperature threshold has been used to define the oceanic warm pool (OWP), which in the present era covers nearly $30 \%$ of the global ocean surface. Summing the total vertically integrated heating over the ocean in $1{ }^{\circ} \mathrm{C} \mathrm{SST}$ bins shows that, on average, 25,48 and $27 \%$ of the total heating occurs currently in the $27-28,28-29$ and $29-30^{\circ} \mathrm{C}$ SST bins, respectively. Outside of the region where $\mathrm{SST}<T_{H}$, there are broad areas of negative $\mathrm{CIH}$ resulting principally from long-wave radiative cooling.

Figure 3 shows the seasonal variation of the patterns of CIH for the period 1957-2001. A global analysis of CIH was performed by Chan and Nigam (2009) although for a somewhat shorter period. Their main emphasis was to compare the $\mathrm{CIH}$ calculated from different reanalysis data sets with the heating profiles obtained by Tao et al. (2001) based on data from the Tropical Rainfall Measurement Mission. Our emphasis is different in that we seek to identify relationships of the CIH with the evolving SST distribution. Although, most atmospheric heating occurs over the OWP there are small regions of heating off the extratropical coasts in the northwest Pacific and Atlantic due primarily to the heating of cold continental air flowing over the warm ocean western boundary currents during winter, and from elevated heating from large mountain ranges during summer. Specifics of the regional details will be the subject of another study. Here we are more interested in the broad scale features of the CIH distribution. b Total tropical atmosphere $\mathrm{CIH}$ in the $30^{\circ} \mathrm{S}-30^{\circ} \mathrm{N}$ band plotted in $1{ }^{\circ} \mathrm{C}$ SST bins. The black line shows the average column integrated heating in each SST interval. 25, 48 and $27 \%$ of the total heating occurs between the $27-28,28-29$ and $29-30^{\circ} \mathrm{C}$ SST contours, respectively

Figure 3 also shows that the spatial structure of the atmospheric heating varies considerably from season to season in close association with the evolution of SST and solar heating. During the boreal winter, heating is concentrated over the OWP and the southern hemisphere continental areas in addition to heating over the northern hemisphere western boundary currents. During the boreal summer atmospheric heating occurs over the OWP differing spatially to winter patterns, particularly in the Indian Ocean and the South Pacific Convergence Zone, and over the northern hemisphere land masses. The boreal summer heating over the western boundary currents is reduced in magnitude and extent compared to that during boreal winter.

\subsection{Twentieth and twenty-first century OWP}

Analysis of twentieth century ocean-atmosphere coupled simulations for different combinations of anthropogenic and natural forcing (Meehl et al. 2004) indicates that the most likely cause of the OWP expansion is the enhanced concentration of atmospheric $\mathrm{CO}_{2}$. Increased $\mathrm{CO}_{2}$ concentration during the twentieth century explains about $60 \%$ of the observed increase in the area of the OWP, far larger than the impacts of volcanoes, aerosols and etc. Specifically, the PCM simulations only show an expanding OWP area when green house gas forcing is included in the total forcing. At the same time, it should be noted that internal variability in many models is smaller than observed and that there is less skill in simulating oscillations of the couple ocean-atmosphere system than the variability associated with external forcing. 
(a) DJF
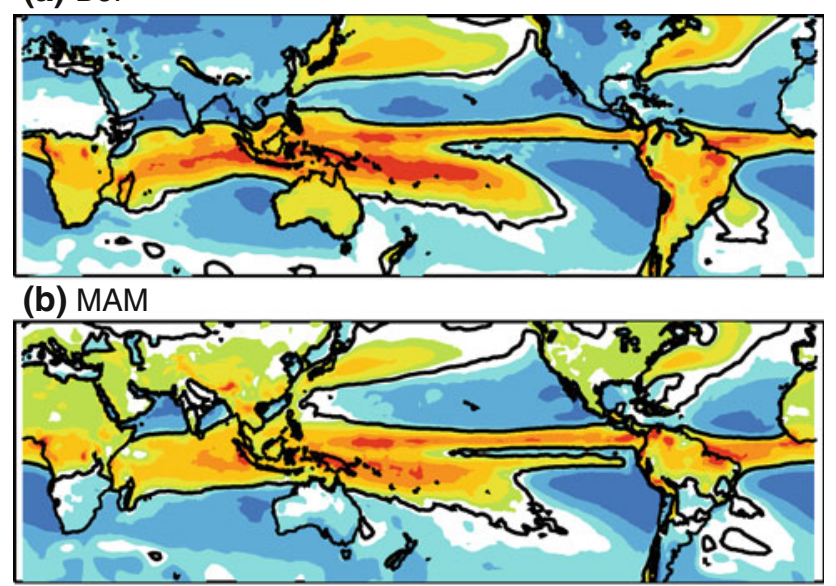

(c) JJA

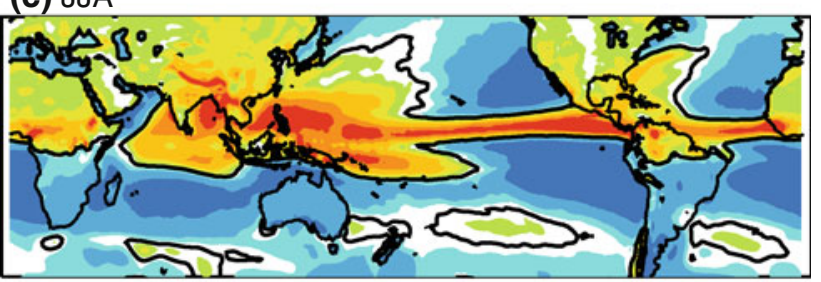

(d) SON

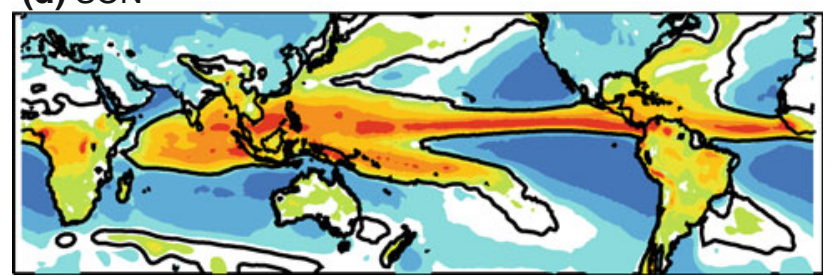

Column Integrated Heating $\left[\mathrm{W} / \mathrm{m}^{2}\right]$

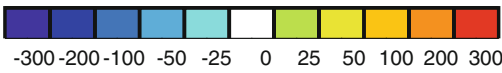

Fig. 3 Annual cycle of CIH: a December, January and February; b March, April and May; c June, July and August; and d September, October, and November from ERA-40 Atlas for the 1957-2001 period

Figure 4 shows the evolution, in 5-year blocks, of the uncorrected tropical OWP area from 1920 to 2000, as simulated by eight different ocean-atmosphere coupled models from the CMIP3 dataset. ${ }^{1}$ The relationship between of the observed and simulated OWP area relative to their corresponding long-term means are also shown as scatter plots, including their cross-correlations. Whilst the magnitude of the OWP area is different between models, owing to their different resolutions, all models simulate the observed OWP expansion during the twentieth century remarkably well with cross-correlations ranging from 0.68

\footnotetext{
1 The models that were selected are NCAR CCSM3, NCAR PCM1, NASA GFDL-CM2.1, NASA GISS, MIROC3.2-MEDRES, ECHAM5/ MPI-OM, UKMET-HadCM3, CSIRO-Mk3.5. Details of the models and the CMIP3 process can be found at: https://esg.llnl.gov:8443/.
}

to 0.86 . Correlations between the observed and the simulated area of SST $>26.5^{\circ} \mathrm{C}$ are also high $(\sim 0.8$ correlations). All correlations are significant at a level greater than $99 \%$.

In order to account for model biases and to obtain a multi-model estimation of the OWP (area $>28^{\circ} \mathrm{C}$ ) and the area where $\mathrm{SST}>26.5^{\circ} \mathrm{C}$ during the twentieth century, as well as the projected changes during the twenty-first century, the simulated OWP and area with SST $>26.5^{\circ} \mathrm{C}$ are statistically corrected relative to the twentieth century observations. Specifically, linear least square regressions between the observed and the simulated OWP area for each model during the twentieth century are used to adjust the magnitude of model biases statistically during the twentieth and twenty-first century. Note though, all models reproduce the observed increase in OWP reasonably well before the bias correction (Fig. 4). All corrections, introduced by the linear fitting equations, only account for the magnitude of the increase and not for the sign of the tendencies. Figure 5 shows the bias-corrected changes in OWP and area of SST $>26.5^{\circ} \mathrm{C}$ from the CMIP3 simulations for different emission scenarios. The figure includes the multi-model biascorrected ensemble mean and the variability estimated as \pm 1 standard deviation of the different bias-corrected model simulations (see inset, Fig. 5). The correlation between the observed and multi-model simulated OWP area is 0.82 for the 1920-2000 period. This correlation is significant at a level greater than 99\%. Projecting into the future, and considering the COMMIT scenario, the OWP and the area of SST $>26.5^{\circ} \mathrm{C}$ stabilizes in about $30-40$ years to a level around 10-20\% greater than in 2000-2004. Under scenarios $\mathrm{A} 1 \mathrm{~B}$ and $\mathrm{A} 2$, the OWP area continues to increase during the twenty-first century to a multi-model average of +70 and $+90 \%$ by 2100 , respectively, relative to the $2000-2004$ value. For the area of SST $>26.5^{\circ} \mathrm{C}$, the increase is +30 and $+40 \%$, respectively, for scenarios A1B and A2.

The spatial distribution of the observed OWP area for the 1920-1925, 1960-1965, 2000-2005 pentads is shown in Fig. 6. In addition, the projected areas for 2030-2035, 2060-2065 and 2090-2095 pentads are also shown for the A1B scenario (Fig. 6). The contours for the twenty-first century OWP area are determined by projecting the relative area changes from the multi-model ensemble onto the 2000-2005 average SST with the assumption that the expansion follows the observed spatial SST gradients homogeneously as it did quite closely during the twentieth century. The largest relative changes during the twenty-first century occur in the Atlantic Ocean and the eastern Pacific, while smaller changes are seen in the western Pacific. By 2060, the OWP in the Atlantic spans from Central and South America to Africa throughout the entire annual cycle, the western Pacific area merges with the Eastern Pacific during all seasons, and in the eastern Pacific this 

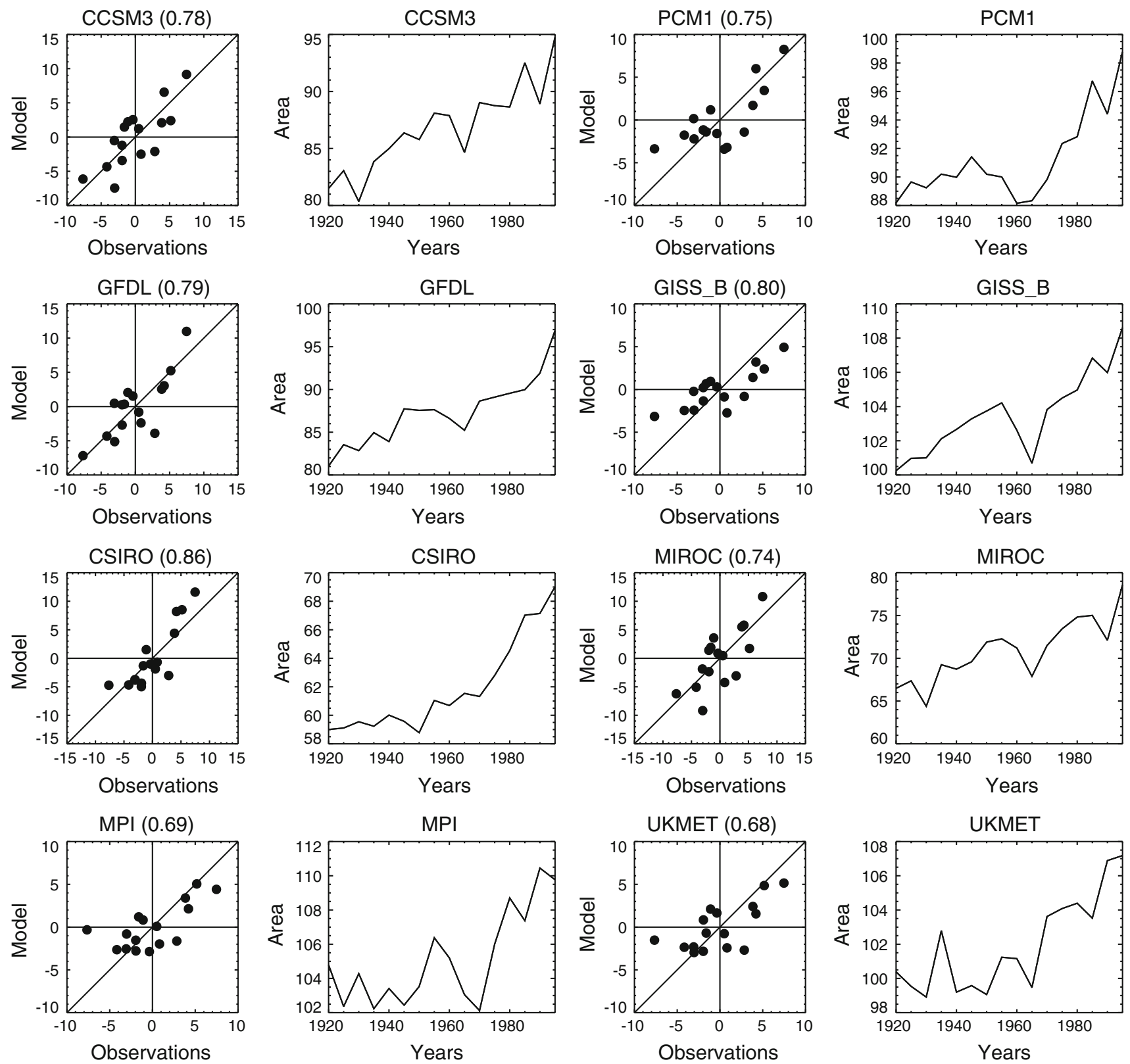

Fig. 4 Observed twentieth century changes in area of SST $>28^{\circ} \mathrm{C}$ between 1920 and 2000 versus the changes in area in each of the selected CMIP3 models for the twentieth century between 1920 and 2000. Models used are listed in the text

region is no longer confined to the northern hemisphere during spring. Changes in the Indian Ocean are particularly large for fall and winter seasons: by year 2060, the fall OWP spans across the entire Indian Ocean from Africa to Indonesia.

\subsection{Twentieth and twenty-first century $\mathrm{CIH}$ and its} relationship with SST: the dynamic warm pool

The 50-year evolution of the CIH as a function of SST between $20^{\circ} \mathrm{S}$ and $20^{\circ} \mathrm{N}$ is computed using the NCEPNCAR and ECMWF ERA-40 reanalyses. Figure 7a shows the co-evolution of the SST and total CIH from 1950 to 2004. The relationship is non-stationary. The CIH profiles shift to higher SSTs so that as the average tropical SST increases, the threshold temperature $T_{H}$ also increases (Fig. 7b). During the last 50 years, $T_{H}$ increased almost linearly with the average tropical SST about $0.5^{\circ} \mathrm{C}$ from 26.6 to $27.1^{\circ} \mathrm{C}$ (Fig. 7b). In addition, there has been $\sim 15 \%$ increase in net heating within the areas of convection during the last 50 years (Fig. 7b). Similar results are obtained using ECMWF ERA-40 reanalysis (Fig. 7c, d). There are some differences between the NCEP and ERA-40 estimations although the progression of $T_{H}$ 


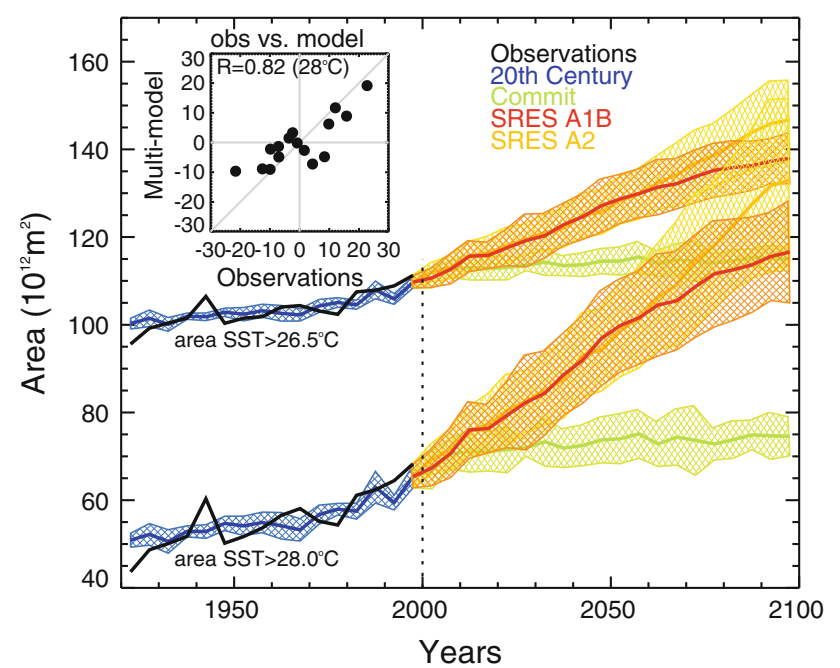

Fig. 5 Changes in area of SST $>28$ and $26.5^{\circ} \mathrm{C}$ from observations (black) and from selected CMIP3 coupled models for the twentieth century runs (blue) and for the following scenarios: COMMIT (green), A1B (red), and A2 (orange) scenarios. The inset shows the relationship between the observed twentieth century changes in area of SST $>28^{\circ} \mathrm{C}$ versus the relative area changes in the multi-model ensemble mean of the selected WCRP CMIP3 models for the twentieth century for the 16 pentads between 1920 and 2000. Quantities shown are deviations from long-term mean

and the trends in net heating are very similar. Chan and Nigam (2009) also found differences between the two estimates of CIH especially across Indonesia. Our biggest difference occurs around 1970, a period that was not contained within the Chan-Nigam analysis.

Estimates of future changes in $\mathrm{CIH}$ under different emission scenarios are evaluated using the CMIP3 simulations. Figure 8 shows time-SST sections of tropical CIH between $20^{\circ} \mathrm{S}$ and $20^{\circ} \mathrm{N}$ for the twentieth and the twentyfirst centuries (A1B scenario) for four different CMPI3 models. Results from other CMIP3 models are similar, with all models indicating that $T_{H}$ increases with time as SST increases. Overall, by $2100, T_{H}$ would be about $1.6^{\circ} \mathrm{C}$ degrees higher than the present day value of $\sim 27^{\circ} \mathrm{C}$.

Our findings are in agreement with the results of other studies (e.g. Lau et al. 1997; Dutton et al. 2000; Williams et al. 2008; Sud et al. 2008). Simply, given the steadily increasing threshold $T_{H}$, the existence of a fixed convective threshold is not evident in an evolving climate nor does such a constant $T_{H}$ have, as we will develop, a reasonable physical basis.

Figure 9a shows the area of positive CIH (heavy black line: termed DWP or dynamic warm pool for later reference) during the twentieth century and for the IPCC A1B emission scenario in the twenty-first century for four different CMIP3 models. In spite of the expansion of the areas above different static SST thresholds, the area of positive heating region does not show any significant long-term trends, covering about $25 \%$ of the global ocean or about $60 \%$ of the ocean area between $20^{\circ} \mathrm{S}$ and $20^{\circ} \mathrm{N}$. The area of the OWP for each of the scenarios is shown for comparison. Similar results are obtained for COMMIT and IPCC A2 scenarios (not shown). Thus, while the SST and the area of the OWP area increase sharply with time, the area of net heating in the tropics (the DWP), remains remarkably constant over the twentieth and twenty-first century.

Dutton et al. (2000) also noted a constancy of the area of deep tropical convection defined by out-going longwave radiation and increasing threshold temperatures as $\mathrm{CO}_{2}$ concentrations increase in a set of coupled general circulation model experiments. Rather than a static definition set by a constant temperature, the climatically active warm pool is defined dynamically by the large-scale coupled ocean-atmosphere system, and as previously stated, corresponds to the area where SST $>T_{H}$ enclosing the area of positive $\mathrm{CIH}$.

Figure $9 \mathrm{~b}$ shows the change in $\mathrm{CIH}$ relative to the year 2000 value in each of the models. Despite the near constancy of the area of positive $\mathrm{CIH}$, the magnitude of heating within the area increases substantially in the twentieth and twenty-first century simulations. The increase during the twentieth century is similar to that calculated from the reanalysis products (Fig. 7). The change in magnitude of the net heating is particularly sharp during the twenty-first century with a $20 \%$ increase relative to the simulated 1995-2000 values. Such projected increase in $\mathrm{CIH}$, together with a constant area of positive heating would suggest a more vigorous circulation, with intensified moist convection in tropical areas and enhanced subsidence outside the tropics, also leading to a stronger vertical wind shear nearby the convective region's boundaries. The intensified hydrological cycle could have potentially important thermodynamic and dynamic impacts for the tropical as well as the global climate.

In Sect. 4, we discuss how a combination of thermodynamic and dynamic factors the location and size of the DWP to fall within a relatively narrow range.

\subsection{Paleo-CIH/SST distributions and relationships}

Significant changes in climate are not exclusive to the present era and are not necessarily induced by human activities. As mentioned earlier, the LGM and the M-HP are two periods where the Earth's climate was approximately in balance for long periods and significantly different from today's climate. These two periods constitute an opportunity to evaluate whether or not twentieth and twenty-first century changes in OWP and positive CIH area (or DWP) are consistent with past climates under very different conditions. We use the PMIP I and II simulations of the LGM, M-HP and P-IP to estimate changes in the DWP and the magnitude of 
Fig. 6 Spatial distribution of the area of SST $>28^{\circ} \mathrm{C}$ for the 1920-1925 (green), 1960-1965 (blue), 2000-2005 (yellow) pentads from NOAA Extended Reconstructed SST v2 data as well as the 2030-2035 (dotted line), 2060-2065 (dashed line) and 2090-2095 (red) pentads from the A1B scenario (a) DJF

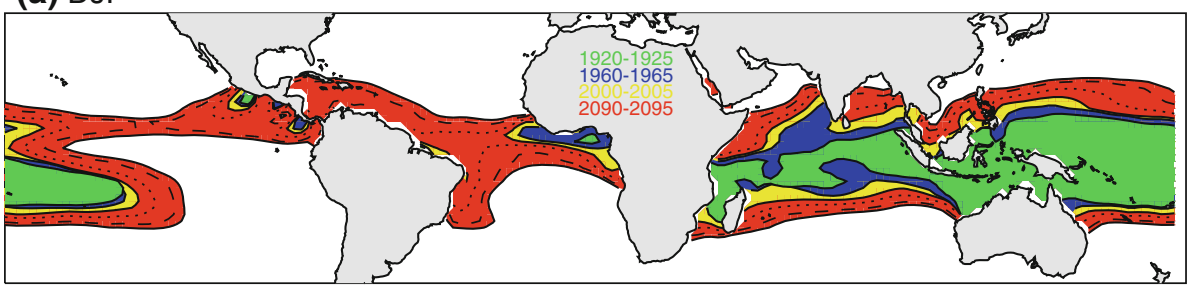

(b) MAM

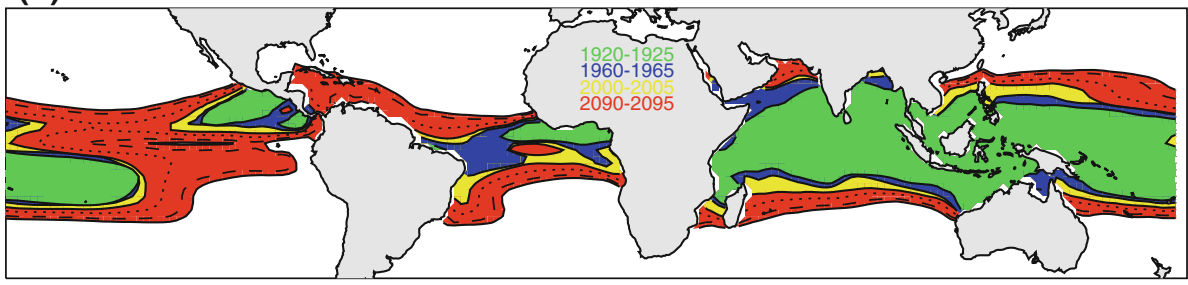

(c) JJA

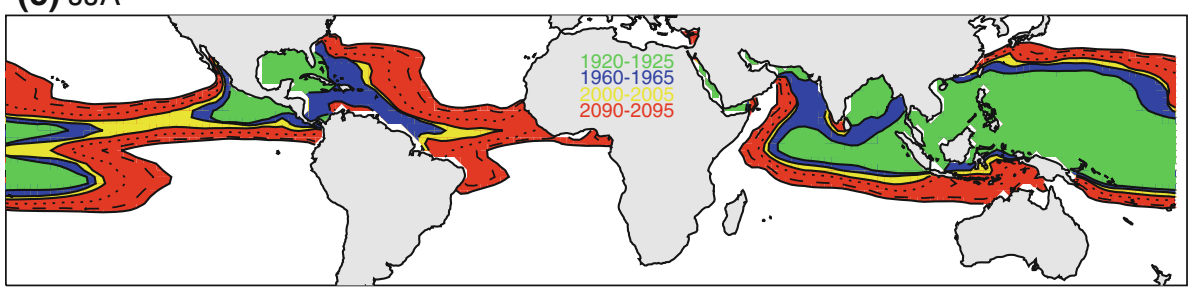

(d) SON

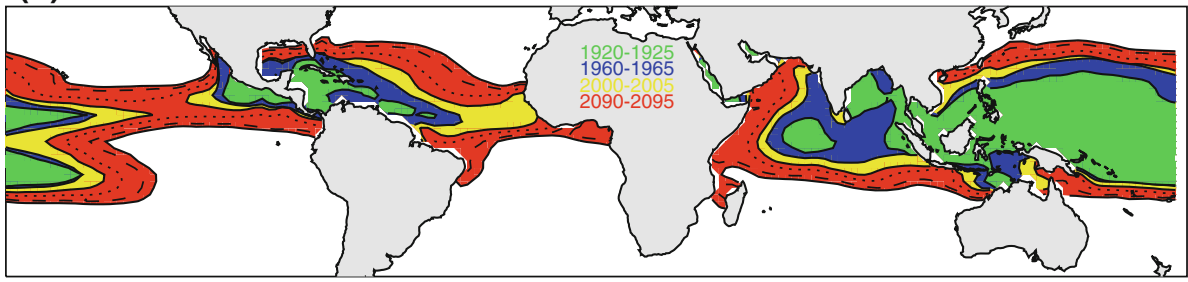

convection and heating within the DWP, relative to changes in tropical SST.

Figure 10 presents a summary of the analysis of four different PMIP I models (NCAR CCM3, Canadian Climate Center model, GFDL, and UGAMP) for the LGM and the P-IP. The PMIP I data that are publically available are not sufficient to calculate $\mathrm{CIH}$ from the scaled version of (1). For this reason, precipitation minus evaporation $(P-E)$ is used as a proxy for net convective heating where we interpret $P-E=0$ as equivalent to a threshold of positive $\mathrm{CIH}$. Figure 10a shows a multi-model average of the SST versus $P-E$ for the LGM and the P-IP depicting a $2 \mathrm{~K}$ change in the SST threshold for $P-E=0$. Figure $10 \mathrm{~b}$ presents a scatter plot of the cumulative positive $P-E$ (i.e. the sum of the residual $\mathrm{P}-\mathrm{E}$ where the residual is positive) in the $30^{\circ} \mathrm{S}-30^{\circ} \mathrm{N}$ band for the LGM and P-IP periods. These represent a proxy for the relative change in convective activity between the two periods. It is important to note that while the four models vary widely in their simulations of total positive $P-E$ (ranging from 1,800 to $8,000 \mathrm{~mm}$ in the P-IP) all the four models show larger magnitudes of total positive
$P-E$ (more precipitation exceeds evaporation) during the warmer P-IP compared to the colder LGM. The increase is about $6 \%$. Figure 10c shows the change in area of positive $P-E$. Three out of the four models show a slight reduction in area $(<0.5 \%$ in magnitude) in the P-IP compared to the LGM while one model shows a $2 \%$ increase. Ostensibly, the area is constant between the two climate epochs. Figure 10d summarizes the results of PMIP I analysis and indicates that the change in convective activity is about 5-10 times larger than the change in the size of the convective region.

Results using the PMIP II simulations are summarized in Fig. 11. The analysis includes six different models. ${ }^{2}$ Figure $11 \mathrm{a}$ shows the standardized average $\mathrm{CIH}$ in each $0.5^{\circ} \mathrm{C}$ bin for the LGM, M-HP and the P-IP plotted against SST, relative to the P-IP. In other words, for each of the models, the SST versus CIH curves are plotted after subtracting $T_{H}$ in the P-IP in the corresponding model from the SST values.

\footnotetext{
${ }^{2}$ NCAR CCSM, CNRM CM33, Hadley Center CM3M2, LASG FGOALS, and MRI CGCM2.3.4. See http://pmip2.1sce.ipsl.fr/ for details.
} 
(a) Pentad ClH (SST) 1950-2004 (NCEP)

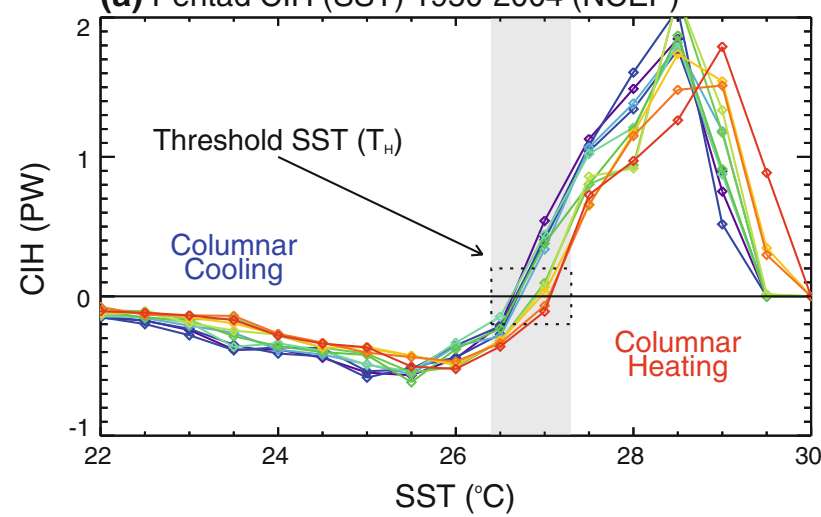

(c) Pentad CIH (SST) 1960-2000 (ECMWF)

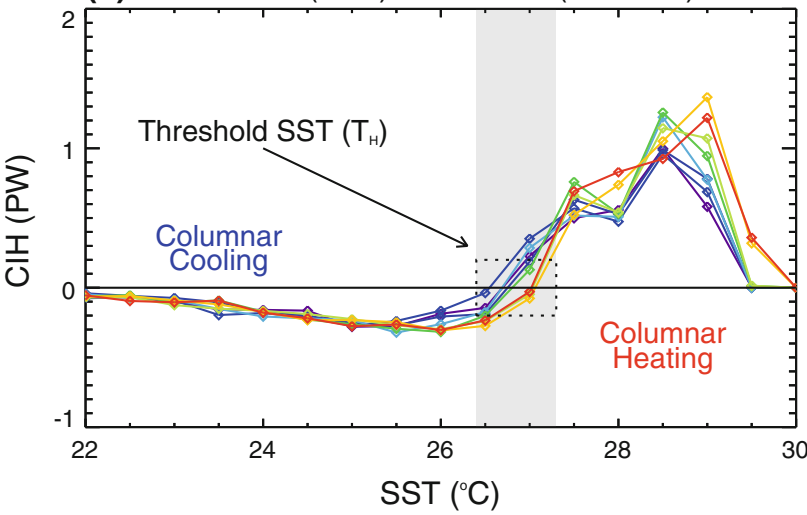

(b) Pentad $\mathrm{T}_{\mathrm{H}}$ and Net Heating

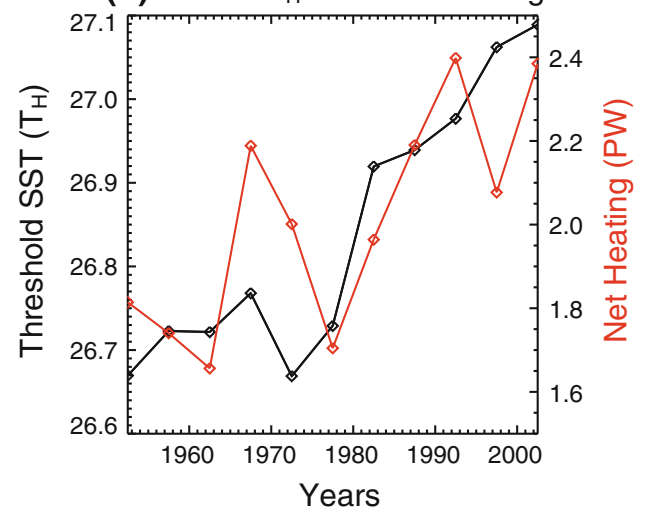

(d) Pentad $\mathrm{T}_{\mathrm{H}}$ and Net Heating

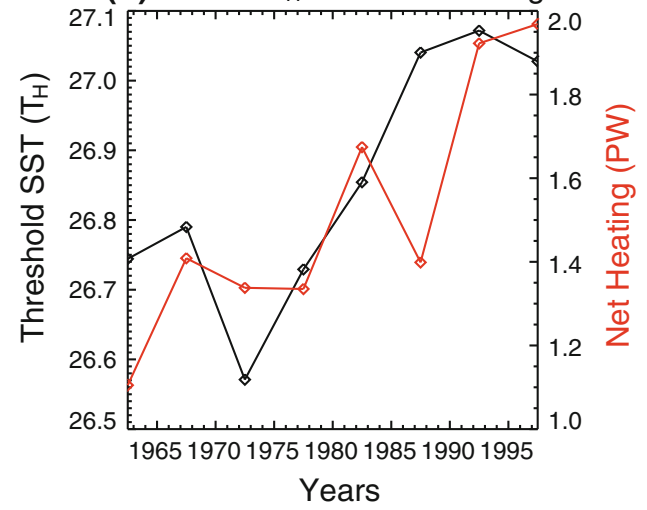

Fig. 7 a Pentad evolution of the total tropical CIH binned every $0.5^{\circ} \mathrm{C}$ SST from 1950-1954 to 2000-2004 using the NCEP-NCAR reanalysis and the NOAA Extended Reconstructed SST v2. Different colours represent different pentads: cold colours represent pentads closely to 1950-1954 (shown in purple) with warm colours representing pentads closer to 2000-2004 (shown in red). The dotted box

Note that all curves corresponding to the P-IP cross from negative to positive $\mathrm{CIH}$ at zero relative SST. Also, the standardization is performed by dividing the average $\mathrm{CIH}$ values by the maximum absolute average $\mathrm{CIH}$ value in each model run, thus obtaining values ranging from -1 to 1 . The average $\mathrm{CIH}$ is presented in a standardized manner and the SST is shown relative to the corresponding $T_{H}$ in the P-IP to allow a direct comparison among the different climate periods, leaving aside differences among model climatologies due to their varying resolutions, differences in parameterizations and biases. The variation in average temperature for a given climate period among models could be as much as $1 \mathrm{~K}$. PMIP II simulations show an average $2 \mathrm{~K}$ difference in $T_{H}$ between the P-IP and the LGM, while during the M-HP the $T_{H}$ is almost the same as in the P-IP. The thresholds calculated from the models are $24,25.8$ and $26^{\circ} \mathrm{C}$ for LGM, M-HP and P-IP conditions, respectively, noting that the current threshold temperature for convection is about $27^{\circ} \mathrm{C}$ (Fig. 3b). highlights the changes of the SST-threshold temperature $T_{H}$ for atmospheric heating for different pentads. d Pentad evolution of $T_{H}$ (black line), and net heating in the tropics (red line) from 1950-1954 to 2000-2004. c and d similar to a and b, respectively, but using ERA-40 reanalysis from 1960-1964 to 1995-1999

Figure $11 \mathrm{~b}$ shows the area of SST $>26,27$ and $28^{\circ} \mathrm{C}$ for the three different periods. The diagram also shows the SST thresholds $T_{H}$ (right-hand scale). The results are similar to the PMIP I, CMIP3 and twentieth century observations. As temperature increases relatively from one period to another, the OWP also increases, but so does the convective threshold rendering the DWP almost constant in area. Also, both the PMIP I and PMIP II simulations suggest that the net $\mathrm{CIH}$ within the DWP is enhanced as temperature increases, again in agreement with twentieth and twenty-first century results.

\section{Constancy of the area of the dynamic warm pool (DWP)}

If the area of positive $\mathrm{CIH}$ in the tropical oceans remains constant as SST changes, the increased heating within the dynamic warm pool must be balanced by an increased 
(a) NCAR PCM1

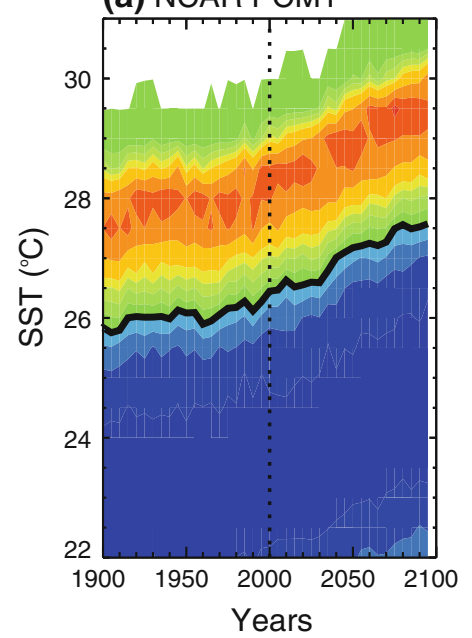

(b) NCAR CCSM3

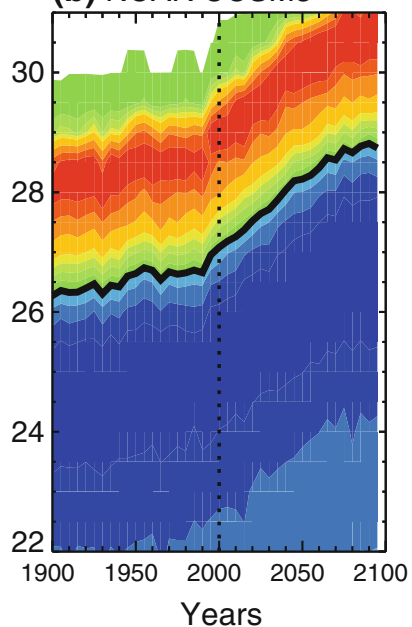

(c) NASA GISS eh

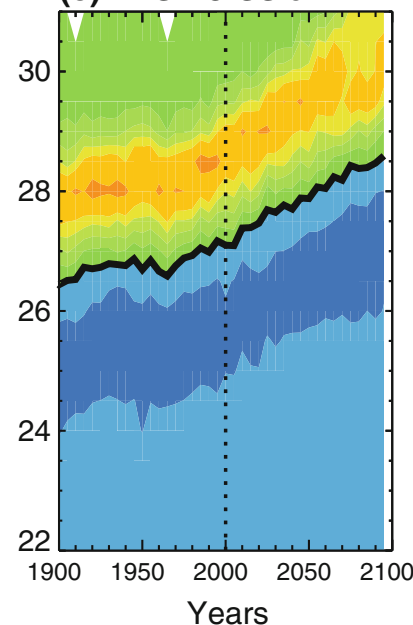

(d) NOAA GFDL CMR.

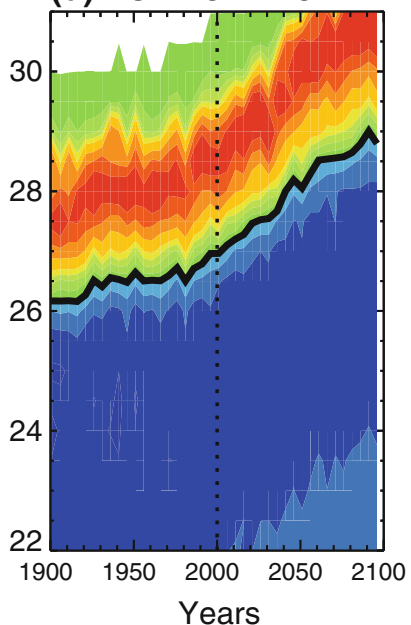

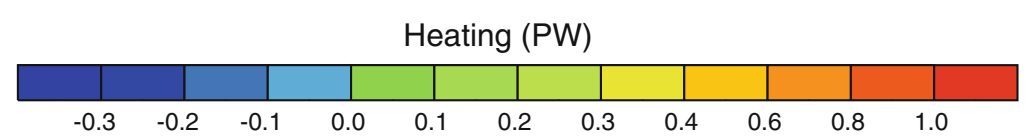

Fig. 8 Evolution of $\mathrm{CIH}$ between $20^{\circ} \mathrm{S}$ and $20^{\circ} \mathrm{N}$ for the twentieth and the twenty-first centuries (A1B scenario) as a function of time and SST for the NOAA GFDL-CM2.1., NCAR PCM1, NCAR CCSM3 and NASA GISS-eh models. The atmospheric heating was integrated in $0.5^{\circ} \mathrm{C}$ SST bins. The black line corresponds to the threshold temperature, $T_{H}$
Fig. 9 a Average evolution of the DWP area in the twentieth century and IPCC A1B (twentyfirst century) scenarios for four different WCRP CMIP3 models (NCAR CCSM3, NCAR PCM1, NOAA GFDL 2.1 and NASA GISS eh). The DWP area does not include bias corrections. OWP area is also shown for the same scenarios for direct comparison. b Net heating over the tropical ocean for the twentieth century and the A1B CMIP3 scenarios relative to the 1995-1999 values (a) DWP and OWP areas

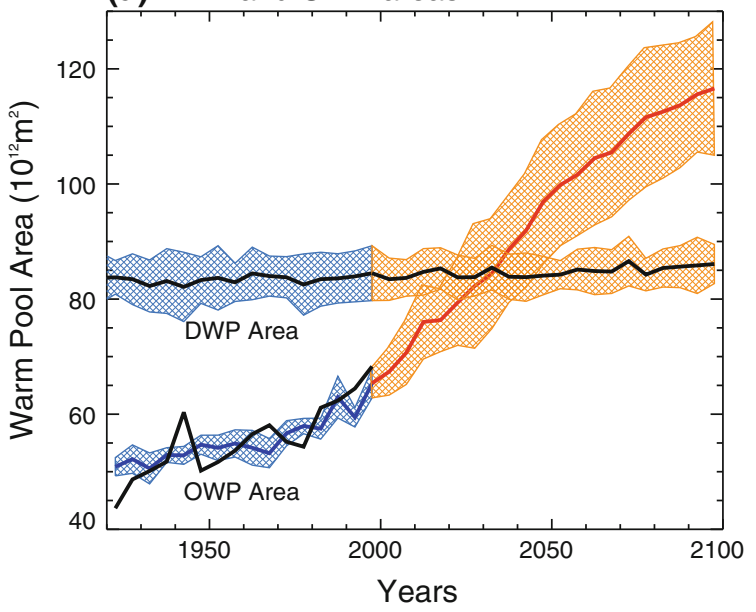

(b) Net heating

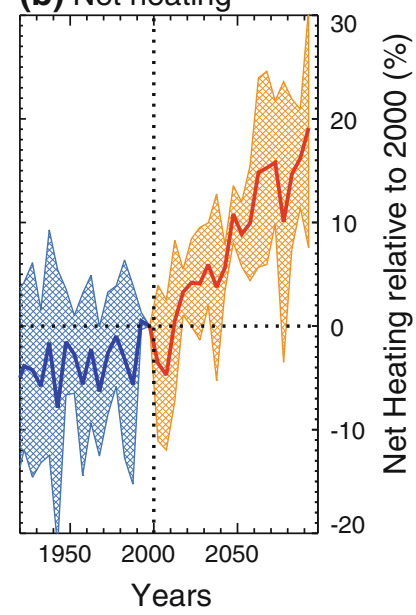

cooling in regions where SST $<T_{H}$. Similarly, in a cooler environment (e.g., during the LGM) where the region of $\mathrm{CIH}>0$ possesses the same area, a similar compensation must occur. We investigate this hypothesis using two simple model prototypes.

The hypothesis posed above suggests that the "vigour" of the tropical circulation will increase as the average SST of the tropics increase. But a number of studies have reached an opposite conclusion: that as SST increases the tropical circulations, especially the Walker Cell, reduces intensity (e.g., Vecchi et al. 2006; Vecchi and Soden 2007). We will return to this issue later noting that a number of other papers (e.g., Zhou et al. 2011; Meng et al. 2011) support a more vigorous tropical circulation, in accord with the conclusions reached in the present study.

Consider a simple "two-box" model of the climate system (Fig. 12a). The first box, corresponding to the area of $\mathrm{CIH}>0$, or the DWP region, is dominated by rising motion and convective latent heat release. The second box encompasses the surrounding colder region, where air is descending and cooling by long-wave radiative (LWR) lost to space. In the cooling box the vertical convergence of heat is given by the difference between the LWR entering the column at the surface and the LWR exiting to space at the top of the atmosphere (TOA). The LWR is given by the Stephan-Boltzman law: 
Fig. 10 Summary of analysis of the PMIP I models (NCAR CCM3, Canadian Climate Center model, GFDL, and UGAMP) for the LGM and P-IP. a Multimodel average of the SST versus $P-E$ for LGM (blue) and P-IP (red). b Scatter plot of the cumulative positive $P-E$ in the $30^{\circ} \mathrm{S}-30^{\circ} \mathrm{N}$ band for the LGM and P-IP. c Scatter plot of area of positive $P-E$ for the LGM and P-IP. d Relative change in positive $P-E$ and positive $P-E$ area between the LGM and the P-IP

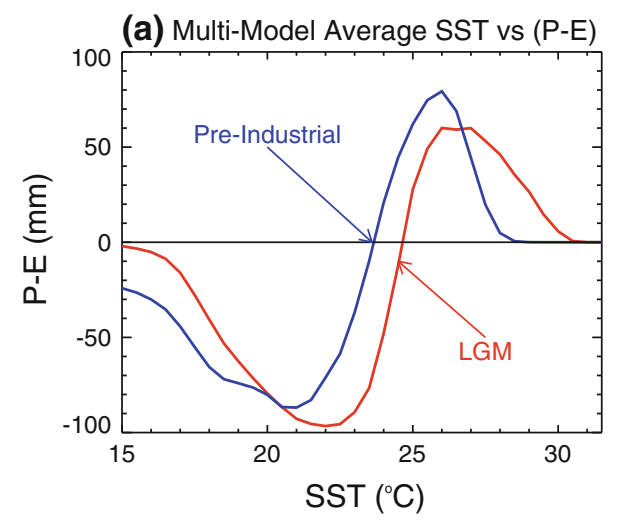

(c) \% Positive P-E: Pre-Ind. vs LGM

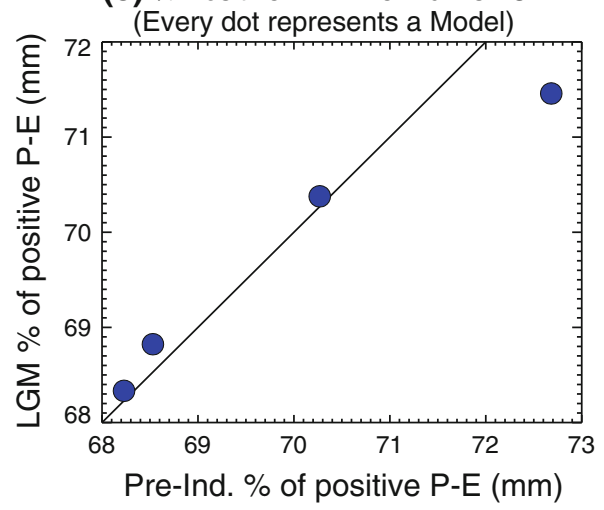

(b) Total Positive P-E: Pre-Ind. vs LGM (Every dot represents a Model)

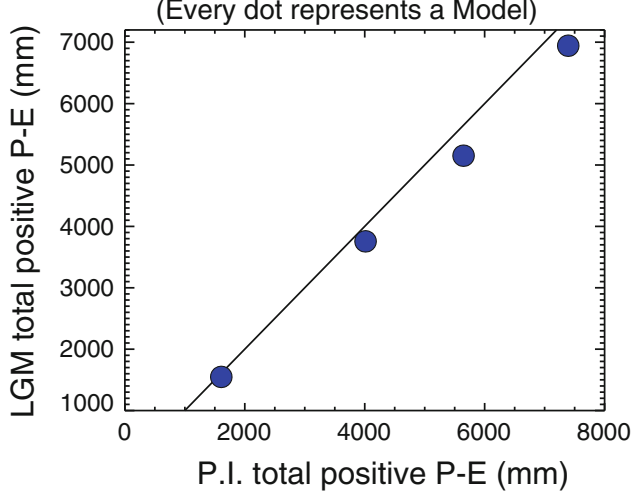

(d) \% Change: $+(\mathrm{P}-\mathrm{E})$ vs $+(\mathrm{P}-\mathrm{E})$ Area

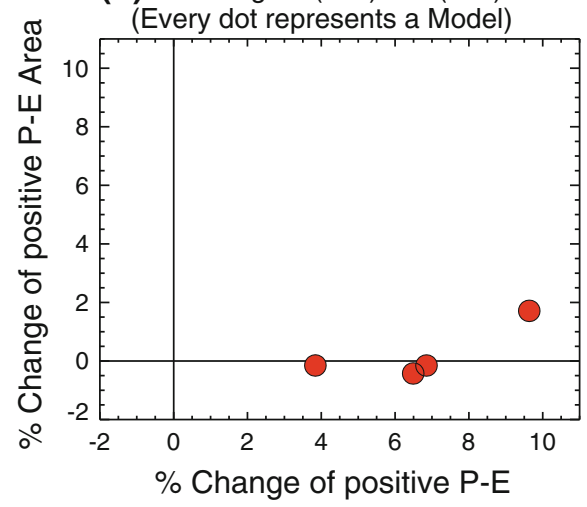

$F_{n e t}=\varepsilon \sigma T^{4}$

where $\varepsilon$ is an emissivity and $\sigma$ the Stefan-Boltzman constant. In the warming box the vertical convergence of heat is given by the difference of LWR at the surface and at TOA plus the atmospheric heating within the column from condensation $\left(L_{E}\right)$ where:

$L_{E}=\rho_{a} L C_{D E} U q_{s}^{*}\left[\left(1-R_{H}\right)+R_{H} L\left(T-T_{a}\right) / R_{v} T^{2}\right]$

after Hartmann (1994). It is assumed, to first approximation, that all evaporation from the warming and cooling boxes condenses within the convective box. In (3), $\rho_{a}, L, C_{D E}, U, q_{s}^{*}$, $R H, R_{v}$, and $T_{a}$, represent the density of air, the latent heat of vaporization, the aerodynamic transfer coefficient for vapor, the surface wind speed $\left(\sim 5-10 \mathrm{~ms}^{-1}\right)$, the saturation specific humidity at the surface, the relative humidity $(\sim 70 \%)$, the gas constant for water vapor and the air temperature.

Assume now that the two boxes are in equilibrium, with convection and heating within the warm box balanced by subsidence and cooling in the colder box. Note that surface evaporation is a nonlinear function that increases exponentially with SST through the Clausius-Clapeyron relationship. The radiative loss is also nonlinear, proportional to the fourth power of temperature through the StefanBoltzmann Law. Over a range of SST between 27 and $32^{\circ} \mathrm{C}$, enclosing the LGM, the M-HP, the P-IP and the present climate as well as what may be expected reasonably in the future, the area of the dynamic warm pool ranges from 23.5 to $21 \%$ of the surface of the idealized planet (Fig. 12b) for a homogeneous SST increase in both the heating and cooling boxes. These values are similar to the $\sim 25 \%$ coverage of convection over ocean found in the CMIP3 models and suggested much earlier by the analysis of Gray (1973) using satellite observations. Thus, for a homogeneous SST increase the area of the DWP will essentially remain constant, with a tendency to decrease slightly as SST increases. This near-constancy suggests that the sensitivity of radiative cooling to space to changes in SST (i.e., $d F_{n e t} / d(\mathrm{SST})$ from Eq. 2) must be almost equal (and opposite) to the sensitivity of latent heat release in within a column to SST (i.e., $d L_{E} / d(\mathrm{SST})$ from Eq. 3). To explore this finding further, experiments were conducted using a relatively simple two-level, nonlinear zonally symmetric model with a full hydrological cycle (Webster and Chou 1980a, b; Webster 1983). The model is adapted to represent an aqua-planet (i.e. no land). The atmospheric component is a primitive equation model extending from pole to pole, with explicit calculation of latent heating due to regional convective effects and large-scale convection depending on moisture availability and equivalent potential temperature following Ooyama (1969) and Anthes (1977). Surface fluxes are calculated at the surface relative to the 
(a) SST vs $\mathrm{CIH}$

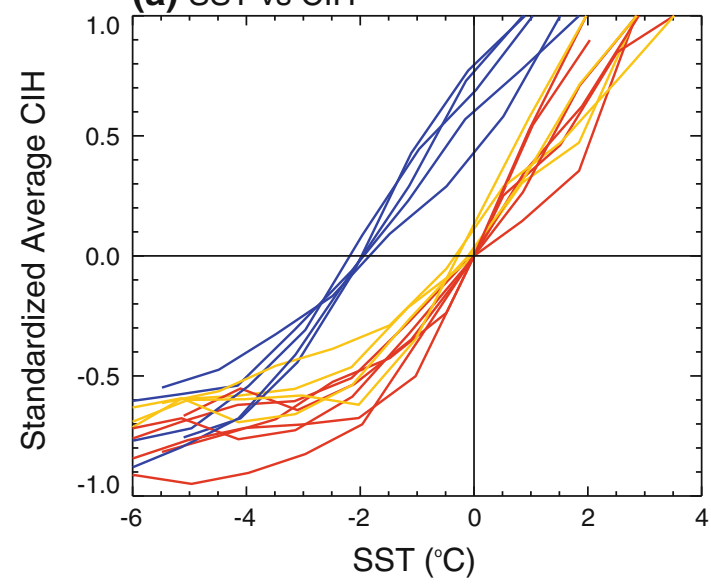

(b)

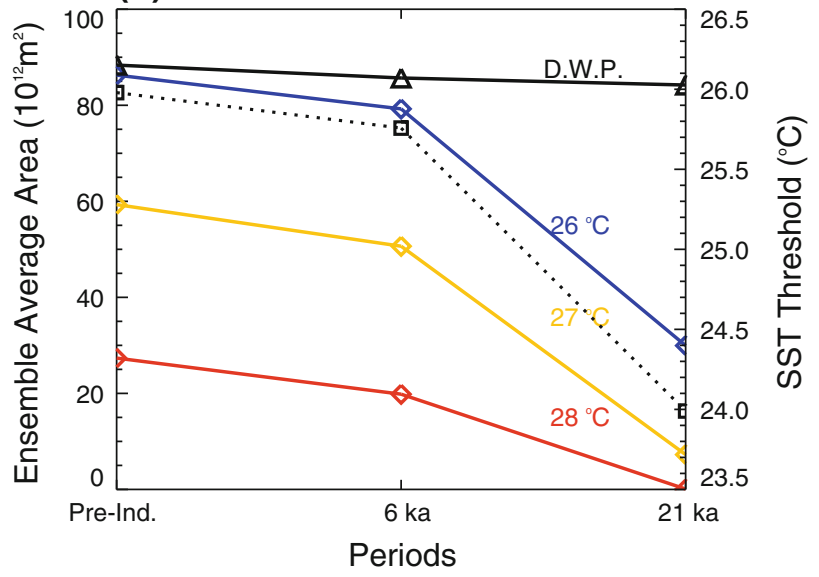

Fig. 11 Summary of analyses of the PMIP II models (NCAR CCSM, CNRM CM33, Hadley Center CM3M2, LASG FGOALS, and MRI CGCM2.3.4) for the LGM, M-HP and P-IP. a SST versus average $\mathrm{CIH}$ in $0.5^{\circ} \mathrm{C}$ bins for the LGM (blue), M-HP (orange) and P-IP (red). The average $\mathrm{CIH}$ is presented in a standardized manner and the SST is shown relative to the corresponding $T_{H}$ in the P-IP. b Area of SST $>26,27$ and $28^{\circ} \mathrm{C}$ as well as the DWP area for the three different periods (black line). The diagram also shows the SST thresholds $T_{H}$ (dotted line)

state of the evolving model atmosphere and the underlying SST. The radiation scheme is configured as a two-stream model following Stephens and Webster $(1979,1984)$.

The atmospheric component of the model is run in uncoupled mode to equilibrium for different SST sinusoidal configurations. Each SST forcing has the same latitudinal distribution so that there is no change in meridional gradient but with different magnitudes due to a homogeneous increase of surface temperature. Figure 13a shows the different SST equatorially symmetric configurations plotted in steps of $1^{\circ} \mathrm{C}$ from 26 to $38^{\circ} \mathrm{C}$. Figure $13 \mathrm{~b}-\mathrm{d}$ show the resulting annual average vertical velocity, vertical wind shear in the meridional direction and $250 \mathrm{hPa}$ temperature. For easier interpretation, the fields are coded in (a) Schematic of dynamic warm pool with increasing SST

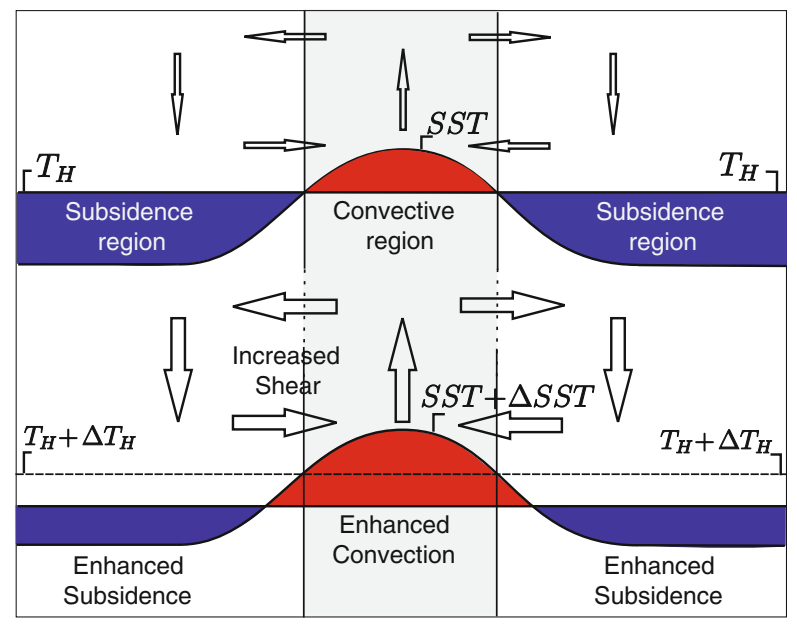

(b) Sensitivity of DWP to SST increase

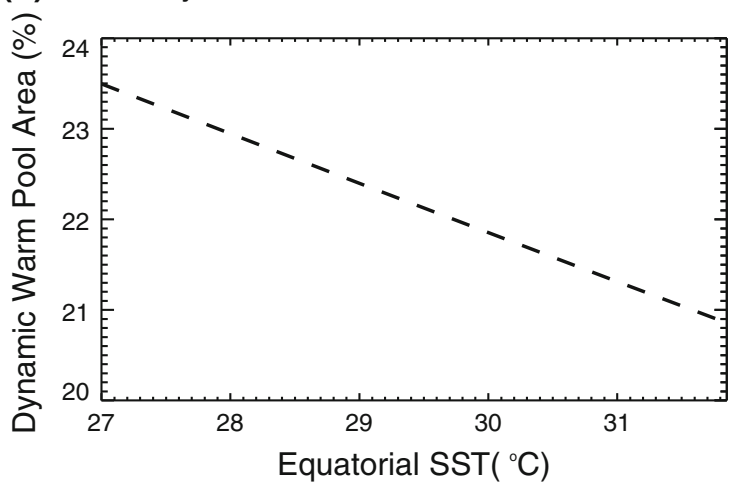

Fig. 12 a Schematic diagram of the "two-box" model containing a convective and a subsidence region. The top panel represents the current state of the climate where it is assumed that the convective $\left(S S T>T_{H}\right)$ and subsidence regions are in dynamical and thermodynamical balance. The bottom panel represents the two-box model after a homogeneous increase in SST in both boxes. Here, the heating threshold SST increases $\left(T_{H}+\Delta T_{H}\right)$, but the convective region remains constant. The balance and constancy of in the climate state is achieved by both enhanced convection and subsidence. b Dynamic warm pool (convective region) size relative to the surface area of the planet in the simple two-box model

the same colors as the SST configuration shown in Fig. 13a. The model simulations result in a zone of narrow convection at the equator and subsidence in both hemispheres poleward of about $15^{\circ} \mathrm{N}$ and $\mathrm{S}$. Both equatorial convection and off-equatorial subsidence increase as the SST forcing increases in magnitude, enhancing the meridional circulation (Fig. 13b) and precipitation. That is, as the base SST increases, the tropical circulations become more vigorous. Also, in accordance with the increased vigour, the meridional vertical wind shear also increases at the edges of the convective cells (Fig. 13c). The upper tropospheric temperature $(250 \mathrm{hPa})$ also increases. The increase of the $250 \mathrm{hPa}$ temperatures is greater at low 
latitudes because of the non-linearity of moist processes (Fig. 13d). Note that while the range of SST variations at the equator is $\sim 10^{\circ}$, the range at the $250 \mathrm{hPa}$ is $\sim 20^{\circ}$. Thus, the dry static energy of the model increases with SST but the moist static energy decreases, or becomes more unstable.

Figure 14 summarizes the changes in the relative area of the convective versus the non-convective regions of the tropics for the box model and the aqua-planet model. The size of the convective area in the zonally symmetric aquaplanet behaves remarkably similar to the two-box model, staying relatively constant, and also with a tendency to slightly decrease with increasing equatorial SST. In addition, results indicate that the total precipitation, the magnitude of the average vertical velocity in the convective region and the vertical wind shear at the edge of the dynamic warm pool increase considerably with SST (Fig. 14).

\section{Summary and conclusion}

In the tropics, the distribution and magnitude of the dominant latent heat release associated with deep convective activity is, at any given time, strongly associated with the distribution of SST. In the 1979-2001 period the net atmospheric heating in the $30^{\circ} \mathrm{S}-30^{\circ} \mathrm{N}$ belt occurs where SST $>27^{\circ} \mathrm{C}$, and the spatially averaged heating increases nonlinearly with SST (Fig. 3b). We argue subsequently that this region of net positive atmospheric heating could be referred to as the dynamic warm pool (DWP) as it is determined not only by the spatial distribution of the SST

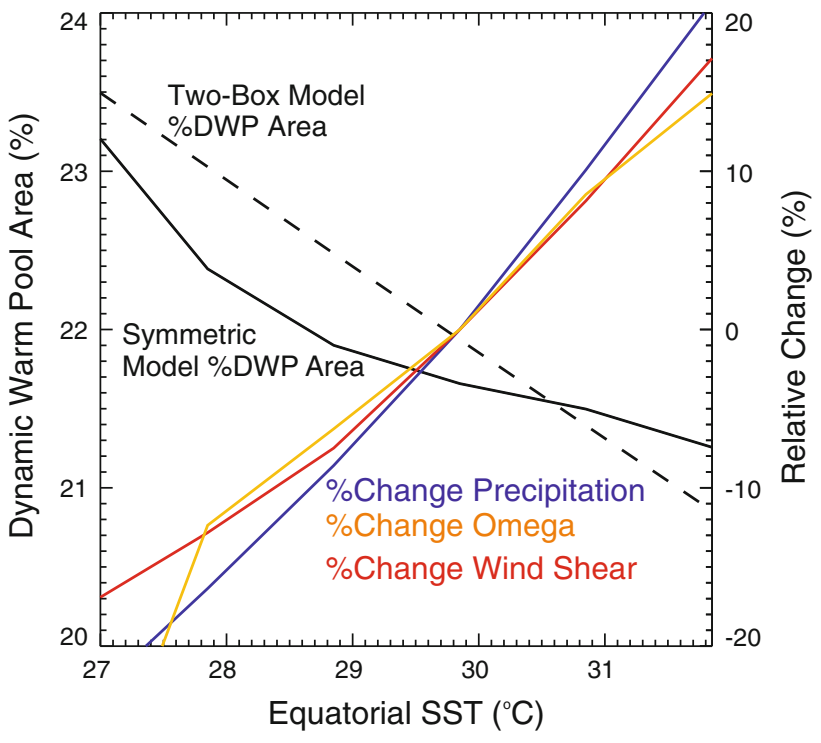

Fig. 14 Size of the DWP relative to the surface area of the planet in a simple two-box model (dashed black line, same as Fig. 12b for comparison), and in the zonally symmetric aqua-planet (continuous black line). Changes of total precipitation (blue line), magnitude of average vertical velocity within the convective region (red line), and wind shear at the edge of the convective region (orange line) are plotted relative to the present $\left(\mathrm{SST} \sim 29^{\circ} \mathrm{C}\right)$

but also the large scale atmospheric circulation. In other words, rather than a static definition set by a constant temperature, the climatically active warm pool is defined dynamically by the large-scale moist coupled oceanatmosphere system.

The nature of the relationship between local and remote SST with local convection during the past, present and
Fig. 13 a Configurations of SST forcing for the zonally symmetric nonlinear global primitive equation model varying the equatorial temperature in steps of $1^{\circ}$ from 26 to $38^{\circ} \mathrm{C}$, b simulated vertical velocity, $\mathbf{c}$ simulated meridional vertical wind shear, and d $250 \mathrm{hPa}$ temperature for each of the SST configurations. The matching colours in all four panels correspond to the same experiment (a) SST Forcing

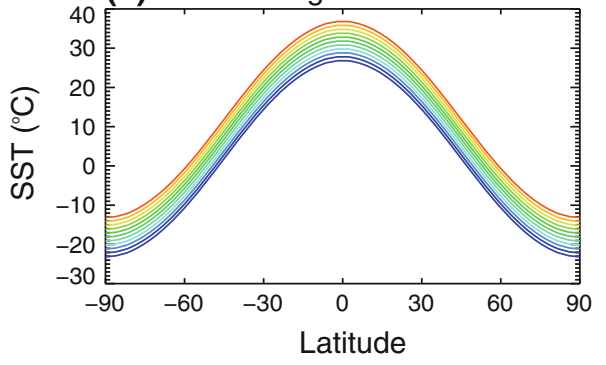

(b) Vertical wind shear

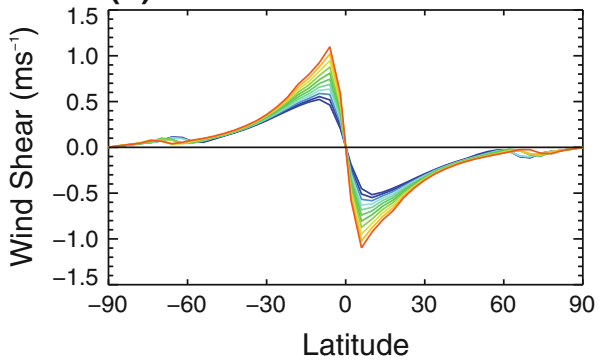

(b) Vertical velocity
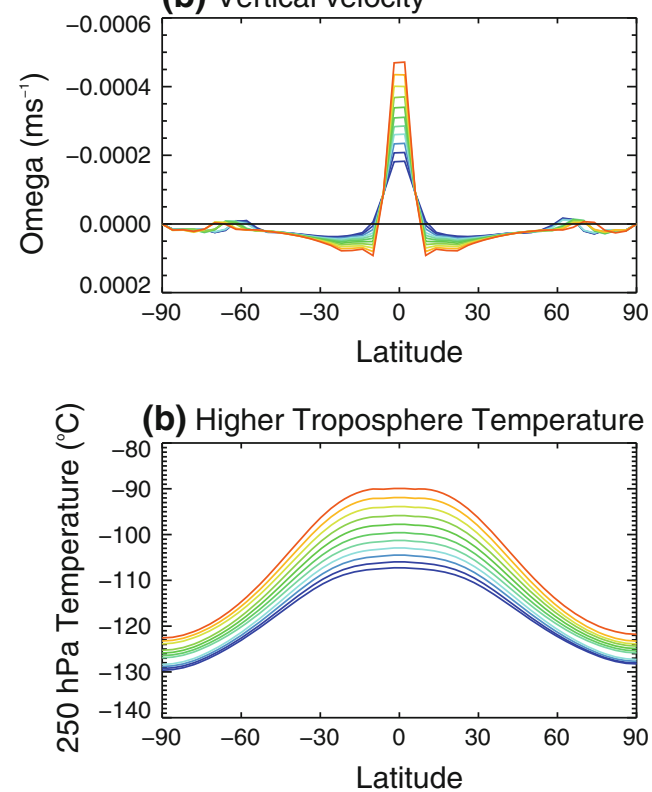
future climate states are determined by examining the evolution of an OWP arbitrarily defined by SST $>28^{\circ} \mathrm{C}$ and the DWP, as well as the magnitude of the net heating within the tropical DWP. Observations and the PCM, CMIP3, and PMIP model simulations are used to study the long-term variability of both forms of warm pool during the Last Glacial Maximum (21 ky BP) and the M-HP period (6 ky BP) compared to P-IP conditions, and their state during the current era and the evolution that may occur during the next century. These different climate epochs correspond to vastly different climate states and differing forcing factors.

During the twentieth century tropical SST has increased by about $0.8^{\circ} \mathrm{C}$ in all tropical oceans accompanied by a steady $70 \%$ expansion of the OWP area, spread uniformly throughout the annual cycle. CMIP3 models are used to assess the twenty-first century changes in OWP and DWP. The models are first bias-corrected using twentieth century simulations. In general, all models simulate the observed twentieth OWP expansion remarkably well although slightly underestimating the steep increase after the 1970s. Multi-model bias-corrected twenty-first century projections indicate that the OWP and the area of SST $>26.5^{\circ} \mathrm{C}$ increase for the COMMIT scenario (i.e., $\mathrm{CO}_{2}$ concentrations held at 2,000 levels) about 10-20\% compared to the 2000-2004 value, while for scenarios A1B and A2 the OWP area increases 70 and $90 \%$.

Analysis of the evolution of $\mathrm{CIH}$ in the tropics during the last 50 years reveals a non-stationary relationship with SST, with CIH profiles shifting to higher SSTs as the SST increases (Fig. 8). CMIP3 simulations behave similarly to observations during the twentieth century and project a further shift of the $\mathrm{CIH}$ profiles to higher SSTs during the twenty-first century. The shift in CIH implies an increase in SST convective threshold. In other words, the transition between different convective regimes (e.g., the onset of deep convection and increases in area averaged $\mathrm{CIH}$ ) while dependant on local SST in the short and medium terms, is not stationary relative to SST. As a result, the DWP area does not vary significantly in the long-term, covering about $25 \%$ of the global ocean. That is, while the SST and the OWP area increase sharply with time, the area of atmospheric convective heating in the tropics remains remarkably constant over the range of climate observed in the twentieth century and the simulated twenty-first century as well as the M-HP and the LGM. In essence, with the warming of SST during the twentieth century, the observational and model results point to an intensification of the hydrological cycle as suggested by Trenberth (1999) with intensified latent heat release within the DWP. These concepts also allow an interpretation of the Lindzen and Nigam (1987) results but for a changing climate. Lindzen and Nigam pointed out the importance of the gradient of
SST in driving the tropical circulation. If the gradient of SST were to remain the same as SST universally increases, one would expect an increase in mass convergence from Clausius-Clapeyron considerations consistent with the results of the simple models presented in Sect. 4.

Paleoclimate simulations (PMIP I and II) for the LGM and the M-HP are in agreement with the results from CMIP3 simulations and twentieth century observations, with enlargement of the OWP as temperature increases relatively from one period to another, and a shift in the convective SST threshold rendering the DWP almost constant in area. The OWP during the M-HP and the P-IP appears considerably larger than during the LGM. But, the LGM convective threshold is about $2^{\circ} \mathrm{C}$ lower than either the M-HP or the P-IP while maintaining a nearly constant DWP area (Fig. 11). With a lower threshold temperature, the integrated heating in the LGM DWP is considerably smaller than the other periods considered (Fig. 11a) leading to a hydrological cycle of probably reduced vigour. This reduction is consistent with the relative aridity occurring in the tropical regions during the LGM (Webster and Streten 1978; Pinot et al. 1999).

The magnitude of $\mathrm{CIH}$ within the DWP increases substantially in the different twenty-first century model simulations accompanying the projected SST rise with an estimated increase of about $20 \%$ in heating relative to present day values. This increase implies an enhancement of the global hydrological cycle, with an intensified circulation, both in the ascending and descending branches, resulting in a more vigorous vertical shear. In fact, analysis of two simple climatic and atmospheric circulation models suggest that, in a range of temperatures enclosing the present climate and what may be expected reasonably in the future, the increase heating within the warm pool is in near balance with increase cooling outside following an increase in global SST and leading to a nearly constant dynamic warm pool area.

One of the major conclusions form this study, that the tropical circulation has become more vigorous during the period of warming since the P-IP, with expectations of further enhancement in the twenty-first century is contrary to a number of studies. For example, Vecchi et al. (2006), Held and Soden (2006) and Vecchi and Soden (2007), using a reanalysis data set, as well as suites of AMIP3 models, argue that the Walker and Hadley circulations have reduced their intensity and will continue to reduce their intensity in a world of warming SST. Held and Soden (2006) have developed a heuristic thermodynamic argument to explain increases in lower tropospheric moist (accompanying SST increases), increased precipitation but lower mass flux. Mitas and Clement $(2005,2006)$ note that reanalysis products have indicated accelerations of both the Hadley and Walker Circulations during the last 
30-40 years differing substantially from the Vecchi et al. (2006) conclusions. They also note that reanalysis products indicate a cooling of the mid-upper troposphere during the late twentieth century, contrary to the models that suggest generally a warming in the mid-upper troposphere. These differences in warming may explain differences in static stability that may help explain a reduction or acceleration of the large-scale tropical circulations. Zhou et al. (2011) use data sets independent of the reanalysis products (the Global Precipitation Climatology Program: GPCP, Adler et al. 2003, and the International Satellite Cloud Climatolgy Progrect: ISCCP, Rossow and Schiffer 1999) to determine the changes occurring in the Walker and Hadley cells. In agreement with Mitas CM and Clement (2005, 2006) they find an intensification of the major tropical circulations. In addition, Zhou et al. (2011) find increases in outgoing longwave radiation in the subsident regions of the tropics in accord with a warming SST and increased moisture in the boundary layer. These results are consistent with the results of our simple models presented in Sect. 4.

Meng et al. (2011) note the importance of determining SST gradients accurately both in observations and simulations. They suggest that warming of tropical SSTs has taken place asymmetrically and that if not carefully observed or modelled, errors could be made in determining trends in circulations. They note, especially inter-basin SST gradients between the poorly observed Indian Ocean and the western Pacific Ocean. Consistent with the recent papers Shin and Sardeshmukh (2011) and Shin et al. (2010), Meng et al. (2011) note the importance of models simulating the regional tropical SST patterns with fidelity in order to acertain both present climate or future changes.

Potentially, an intensified hydrological cycle could have important thermodynamical and dynamical implications in tropical and global climate, ranging from the location and amount of convection and rainfall during past and future climates to the vigor of teleconnection patterns between the tropics and higher latitudes, and up-scale and down-scale transfer of energy. For example, the near constancy in DWP area, together with the intensified $\mathrm{CIH}$ and vertical shear are useful in exploring why observations and model simulations suggest a shift in the hurricane distributions towards more intense, yet fewer storms (Bender et al. 2010; Knutson et al. 2010). This particular issue will be addressed in a companion paper. It is argued that the increasing magnitude of the atmospheric heating within the dynamic warm pool is in accord with an increase in the average intensity of tropical cyclones, as disturbances have higher likelihood of intensification in large-scale moist-convective high-CIH environments (Agudelo et al. 2010). However, accompanying the increased heating within the dynamic warm pool is an increase of mass flux in and out of the region of net heating, increasing the vertical wind shear at the peripheries of the dynamics warm pool (Fig. 14). This increase in vertical wind shear may provide a constraint on cyclone formation, potentially limiting the number of tropical cyclones, even as their average intensity increases.

Acknowledgments The research was funded by the National Science Foundation Climate Division Grant ATM-0531771. The authors would like acknowledge colleagues and members of our research group (Paula Agudelo, Judith Curry, Hye-Mi Kim, Violeta Toma, Hai-Ru Chang, James Belanger) for many discussions regarding the results of the study. We appreciate the advice of Sumant Nigam for discussions and advice about vertically integrated heating. We acknowledge Program for Climate Model Diagnosis and Intercomparison (PCMDI) and the WCRP's Working Group on Coupled Modelling (WGCM) for making available the WCRP CMIP3 multimodel dataset. Support of this dataset is provided by the Office of Science, U.S. Department of Energy (DOE). Data from the Parallel Climate Model runs with different anthropogenic and natural forcing were obtained from the U.S. DOE Couple Climate Model Data Archives (http://www.nersc.gov/projects/gcm_data/) trough the Earth System Grid (ESG, http://www.earthsystemgrid.org/). We also acknowledge ECMWF for making the 1979-2001 CIH available to us for this study. ERA-40 reanalysis data used in this study was also supplied by ECMWF. NCEP Reanalysis Derived data provided by the NOAA/OAR/ESRL PSD (Boulder, Colorado, USA) from their Web site at http://www.cdc.noaa.gov/.

Open Access This article is distributed under the terms of the Creative Commons Attribution Noncommercial License which permits any noncommercial use, distribution, and reproduction in any medium, provided the original author(s) and source are credited.

\section{References}

Adler RF et al (2003) The version-2 global precipitation climatology project (GPCP) monthly precipitation analysis (1979-present). J Hydromet 4:1147-1167

Agudelo PA, Hoyos CD, Curry JA, Webster PJ (2010) Probabilistic discrimination between large-scale environments of intensifying and decaying African easterly waves. Clim Dyn 36:1379-1401

Anthes RA (1977) A cumuls parameterization scheme utilizing a onedimensional cloud model. Mon Wea Rev 105:270-286

Bender MA, Knutson TR, Tuleya RE, Sirutis JJ, Vecchi GA, Garner ST, Held IM (2010) Modeled impact of anthropogenic warming on the frequency of intense Atlantic hurricanes. Science 327:454-458

Berger AL (1978) Long-term variations of caloric insolation resulting from earth's orbital elements. Quat Res 9:139-167

Bjerknes J (1969) Atmospheric teleconnections from the equatorial Pacific. Mon Wea Rev 97:163-172

Chan SC, Nigam S (2009) Residual diagnosis of diabatic heating from ERA-40 and NCEP analyses: intercomparisons with TRMM. J Clim 22:414-428

Charney JC (1969) A further note on the large-scale motions in the tropics. J Atmos Sci 26:182-185

Deser C, Phillips AS, Alexander A (2010) Twentieth century tropical sea surface temperature trends revisited. Geophys Res Lett 37:L1071m. doi:10.1029/2010GL043321

Dutton JF, Poulsen CJ, Evans JL (2000) The effect of global climate change on the regions of tropical convection in CSM1. Geophys Rev Lett 27:3049-3052

Emanuel KA, Neelin JD, Bretherton KA (1994) On large-scale circulations in convecting atmospheres. Q J R Meteorol Soc 120:1111-1143 
Fu R, Del Genio AD, Rossow WB, Liu WT (1992) Cirrus-cloud thermostat for tropical sea surface temperature tested. Nature 358:394-397

Furtado JC, Di Lorenzo E, Cobb KM, Bracco A (2009) Paleoclimate reconstructions of tropical sea surface temperatures from precipitation proxies: methods, uncertainties, and non-stationarity. J Clim 22:1104-1123

Gagan MK, Hendy EJ, Haberle SG, Hantoro WS (2004) Post-glacial evolution of the Indo-Pacific warm pool and El Nino-Southern oscillation. Quat Int 118-119:127-143

Gray WM (1973) Cumulus convection and larger scale circulation I. Broadscale and mesoscale considerations. Mon Wea Rev 101:838-855

Hartmann DL (1994) Global physical climatology, vol 56. International Geophysics Series, Elsevier

Hartmann DL, Michelsen ML (1993) Large-scale effects on the regulation of tropical sea-surface temperature. J Clim 6:2049-2062

Held IM, Soden BJ (2006) Robust responses of the hydrological cycle to global warming. J Clim 19:5686-5699

Hollingsworth A, Arpe K, Tiedtke M, Capaldo M, Savijärvi H (1980) The performance of a medium-range forecast model in winter-impact of physical parameterizations. Mon Wea Rev 108:1736-1773

IPCC (2007) Fourth assessment report of the intergovernmental panel on climate change. Available at http://www.ipcc.ch/publications and_data/publication_and_data_reports.shtml

Jousauume $S$ et al (1999) Monsoon changes for 6000 years ago: results of 18 simulations from the Paleoclimate Modeling Intercomparison Project (PMIP). Geophys Res Lett 26:859-862

Kalnay E et al (1996) The NCEP/NCAR 40-year reanalysis project. Bull Am Meteorol Soc 77:437-471

Knutson TR, McBride JL, Chan J, Emanuel K, Holland G, Landsea C, Held I, Kossin JP, Srivatava AK, Sugi M (2010) Tropical cyclones and climate change. Nature Geosci 3:157-163

Knutti R, Allen MR, Furiedingstein P, Friedlingstein P, Gregory JM, Hegerl GC, Meehl GA, Meinshausen M, Murphy JM, Plattner GK, Raper SCB, Stocker TF, Stott PA, Teng H, Wigley TML (2008) A review of uncertainties in global temperature projections over the twenty-first century. J Clim 21:2651-2663

Lau K-M, Wu H-T, Bony S (1997) Sea surface temperature and largescale circulation influences on tropical greenhouse effect and cloud radiative forcing. J Clim 10:381-392

Lea DW, Pak DK, Spero HJ (2000) Climate impact of late quaternary equatorial Pacific sea surface temperature variations. Science 289:1719-1724

Li T, Hogan TF, Chang CP (2000) Dynamic and thermodynamic regulation of ocean warming. J Atmos Sci 57:3353-3365

Lindzen RS, Nigam S (1987) On the role of sea-surface temperature gradients in forcing low-level winds and convergence in the tropics. J Atmos Sci 44:2418-2436

Loschnigg J, Webster PJ (2000) A coupled ocean-atmosphere system of SST regulation for the Indian Ocean. J Clim 13:3342-3360

Mayewski PA et al (2004) Holocene climate variability. Quat Res 62:243-255

Meehl GA, Washington WM, Ammann CM, Arblaster JM, Wigley TML, Tebaldi C (2004) Combinations of natural and anthropogenic forcings in twentieth-century climate. J Clim 17:37213727

Meehl GA, Covey C, Delworth T, Latif M, McAvaney B, Mitchell JFB, Stouffer RJ, Taylor KE (2007) The global coupled climate multi-model dataset: a new era in climate change research. Bull Am Meteorol Soc 88:1383-1394

Meng Q, Latif M, Park W, Kennyside NS, Semenov VA, Martin T (2011) Twentieth century Walker circulation changes and model experiments. Clim Dyn. doi:10.1007/s00382-011-1047-8
Mitas CM, Clement A (2005) Has the Hadley cell been strengthening in recent decades? Geophys Res Lett 32:L030809

Mitas CM, Clement A (2006) Recent behavior of the Hadley cell and tropical thermodynamics in climate models and reanalyses. Geophys Res Lett 33:L01810

Newell RE (1979) Climate and the ocean. Am Sci 67:405-416

Nigam S (1994) On the dynamical basis for the Asian summer monsoon rainfall El-Nino relationship. J Clim 7:1750-1771

Norris RD, Bice KL, Magno EA, Wilson PA (2002) Jiggling the tropical thermostat in the Cretaceous hothouse. Geology 30:299-302

Oberhuber JM (1988) An atlas based on COADS data set. Technical report no. 15, Max-Planck-Institut fur Meteorologie

Ooyama K (1969) Numerical simulation of the life cycle of tropical cyclones. J Atmos Sci 26:3-40

Otto-Bliesner BL et al (2009) A comparison of the PMIP2 model simulations and the MARGO proxy reconstructions for tropical sea-surface temperature at the last glacial maximum. Clim Dyn 32:799-815

Palmer TN, Mansfield DA (1984) Response of two atmospheric general circulation models to sea-surface temperature anomalies in the tropical East and West Pacific. Nature 310:483-485

Pausata FSR, Li C, Wetstein JJ, Nisancioglu A, Battisti DS (2009) Changes in atmospheric variability in a glacial climate and the impacts on proxy data: a model intercomparison. Clim Past 5:489-502

Peltier WR (1994) Ice-age paleotopography. Science 265:195-201

Pierrehumbert RT (1995) Thermostats, radiator fins, and the local runaway greenhouse. J Atmos Sci 52:1784-1806

Pinot S, Ramstein G, Harrison SP, Pretice IC, Guiot J, Stute M, Jousaume S (1999) Tropical paleoclimates at the last glacial maximum: comparison of the Paleomodeling Intercomaprison Project (PMIP) simulations paleodata. Clim Dyn 15:857-874

Polyakov IV, Bekryaev RV, Alekseev GV, Bhatt US, Colony RL, Johnson MA, Maskshtas AP, Walsh D (2003) Variability and trends of air temperature and pressure in the maritime Arctic. J Clim 16:2067-2077

Rahmstorf S (2002) Ocean circulation and climate during the last 100,000 years. Nature 419:207-214

Ramanathan V, Collins W (1991) Thermodynamic regulation of ocean warming by cirrus clouds deduced from observations of the 1987 El Nino. Nature 351:27-32

Raynaud D, Jopuzel J, Barnola JM, Chappellaz J, Lorius C (1993) The ice record of greenhouse gases. Science 259:926-934

Rind D (2000) Relating paleoclimate data and past temperature gradients: some suggestive rules. Quat Sci Rev 19:381-390

Rosenthal Y, Oppo DW, Linsley BK (2003) The amplitude and phasing of climate change during the last deglaciation in the Sulu Sea, western equatorial Pacific. Geophys Res Lett 30. doi: 10.1029/2002GL016612

Rossow WB, Schiffer RA (1999) Advances in understanding clouds from ISCCP. Bull Am Meteorol Soc 80:2261-2287

Seager R, Murtugudde R (1997) Ocean dynamics, thermocline adjustment, and regulation of tropical SST. J Clim 10:521-534

Shin SI, Sardeshmukh PD (2011) The critical influence f the pattern of tropical ocean warming on remote climate trends. Clim Dyn 36:1577-1591

Shin SI, Sardeshmukh PD, Pegion K (2010) Realism of local and remote feedbacks on tropical sea surface temperatures in climate models. J Geophys Res (Atmos) 115: D21110. Published November 2010

Sigman DM, Boyle EA (2001) Glacial/interglacial variability of atmospheric $\mathrm{CO}_{2}$. Nature 407:713-716

Simmons AJ (1982) The forcing of stationary wave motion by tropical diabatic heating. Q J R Meteorol Soc 108:503-534 
Smith TM, Reynolds RW (2004) Reconstruction of monthly mean oceanic sea level pressure based on COADS and station data (1854-1997). J Clim 17:2466-2477

SRES IPCC (2000) Special report on emission scenarios of the international panel on climate change. Available at http://www. ipcc.ch/pdf/special-reports/spm/sres-en.pdf

Stephens GL, Webster PJ (1979) Sensitivity of radiative forcing to variable cloud and moisture. J Atmos Sci 36:1542-1556

Stephens GL, Webster PJ (1984) Cloud decoupling of the surface and planetary radiative budgets. J Atmos Sci 41:681-686

Stephens GL, Webster PJ, Johnson RH, Engelen R, L'Ecuyer T (2004) Observational evidence for the mutual regulation of the tropical hydrological cycle and tropical sea surface temperatures. J Clim 17(11):2213-2224

Sud YC, Walker GK, Zhou YP, Schmidt GA, Lau KM, Cahalan RF (2008) Effects of doubled CO2 on tropical sea-surface temperatures (SSTs) for onset of deep convection and maximum SST: simulation based inferences. Geophys Res Lett 35:L1270

Sun DZ, Liu ZY (1996) Dynamic ocean-atmosphere coupling: a thermostat for the tropics. Science 272:1148-1150

Tao WK et al (2001) Retrieved vertical profiles of latent heat release using TRMM rainfall products for February 1988. J Appl Meteor 40:957-982

Thompson DW, Kennedy JJ, Wallace JM, Jones PD (2008) A large discontinuity in the mid-twentieth century in observed globalmean surface temperature. Nature 453:646-649

Trenberth KE (1999) Conceptual framework of extremes of the hydrological cycle with climate change. Clim Change 42:327-339

Trenberth KE, Branststor GW, Karoly D, Kumar A, Lau NC, Ropelewski C (1998) Progress during TOGA in understanding and modelling global teleconnection patters associated with tropical sea surface temperatures. J Geophys Res Oceans 103:14291-14324

Uppala SM, Kaslberg PW, Simmons AJ et al (2005) The ERA-40 reanalysis. Q J R Meteorol Soc 131:2961-3012
Vecchi AJ, Soden BJ (2007) Global warming and the weakening of the tropical circulation. J Clim 20:4316-4334

Vecchi GA, Soden BJ, Wittenberg AT, Held IM, Leetmaa A, Harrison M (2006) Weakening of tropical Pacific atmospheric circulation due to 16 anthropogenic forcing. Nature 441. doi: 10.1038 /nature 04744

Visser K, Thunell R, Stott L (2003) Magnitude and timing of temperature change in the Indo-Pacific warm pool during deglaciation. Nature 421:152-155

Wallace JM (1992) Effect of deep convection on the regulation of tropical sea-surface temperature. Nature 357:230-231

Webster PJ (1972) Response of the tropical atmosphere to local steady forcing. Mon Wea Rev 100:518-541

Webster PJ (1983) Mechanisms of monsoon transition: surface hydrology effects. J Atmos Sci 40:2110-2124

Webster PJ (1994) The role of hydrological processes in oceanatmosphere interaction. Rev Geophys 32:427-476

Webster PJ, Chou LC (1980a) Seasonal structure of a simple monsoon system. J Atmos Sci 37:354-367

Webster PJ, Chou LC (1980b) Low-frequency transitions of a simple monsoon system. J Atmos Sci 37:368-382

Webster PJ, Lukas R (1992) TOGA-COARE: the coupled oceanatmosphere response experiment. Bull Am Meteorol Soc 73:1377-1416

Webster PJ, Streten NA (1978) Late quaternary ice-age climates of tropical Australasia: interpretations and reconstructions. Quat Res 10:279-309

Williams IN, Pierrehumbert RT, Huber M (2009) Global warming, convective threshold and false thermostats. Geophys Res Lett 36:L21805

Zhou YP, Xu K-M, Sud YC, Betts AK (2011) Recent trends of the tropical hydrological cycle inferred from Global Precipitation Climatology Project and International Satellite Cloud Climatology Project data. J Geophys Res 116:D09101 